\title{
Molluscan remains from Fiji
}

\author{
Katherine Szabó
}

Archaeology and Natural History, The Australian National University

\section{Introduction}

Shell recovered from archaeological sites can give valuable insight to issues of site formation, taphonomy, subsistence, the nature of the environment and environmental change over time. Here, I present a series of shell analyses that can assist in the investigation of several research issues, focusing primarily on ecological issues.

The primary concern is the interaction of prehistoric Fijians with their environment. Firstly, the shell assemblages will be used to give a general idea of the structure and nature of exploited ecological zones. Once this has been established, the species diversity of each assemblage, coupled with an assessment of the relative importance of various exploited species, is used to understand how Fijians went about selecting and procuring molluscs in the past. Approaches to harvesting wild resources have wide-ranging and varied impacts on local environments that may in turn force change in human exploitation tactics. However, change in patterns of environmental exploitation need not stem from an environmental stimulus. These issues will be considered on an assemblage-by-assemblage basis.

\section{Background to the samples}

The molluscan remains discussed in this chapter derive from 11 sites. These are Natunuku, Votua (1996), Kulu, Navatu, Malaqereqere, Ugaga, Qaranioso I and II, Volivoli II and III, and Tuvu. Archaeological sediments were screened through $3 \mathrm{~mm}$ or $4 \mathrm{~mm}$ mesh, and, at all but two sites (Qaranioso I and II), all recovered shell material was retained for further analysis. The first exception is the sample derived from the Qaranioso II rock shelter, where most marine shell was discarded (Anderson et al. 2000:312). The second site where shell was not retained was Qaranioso I, where excavations recovered only sparse Anadara and Turbo, with only two shell fragments present in the analysed sample (see below).

The sites analysed are of different types and ages, and are located within varied landscapes. 
It cannot be expected that assemblages will be patterned in the same way or reflect the same approach to mollusc exploitation. In each case, the surrounding environment and the nature of the site itself (e.g. open/rock shelter, coastal/inland) were taken into account. There are also considerable differences in sample size (Table 20), and some differences in sample retention that require further discussion. Each sample is briefly reviewed below.

\section{Natunuku}

The molluscan assemblage from the Lapita site of Natunuku is one of the largest under discussion, totalling $58.2 \mathrm{~kg}$. Unlike many of the other samples considered, Natunuku is located near a muddy estuary and this location is clearly reflected in the nature of the shell sample. Three excavations were made at Natunuku, with the first two showing clear signs of disturbance through grave-digging and other processes (see Chapter 6). Trench 3 was a larger excavation with a correspondingly larger shell sample. Despite localised disturbance, it most likely provides the best sample of Lapita-age shellfish from Natunuku, and shell material from Trench 3 is used in the following discussions. Preliminary results of shell analysis for this site were presented in Szabó (2001), but have been revised and expanded.

\section{Votua}

Molluscan shell samples were analysed from both Test Pit 1 and Area 1 adjacent to the Tokelau Stream, excavated in 1996. As previously pointed out by Clark et al. (2001:138), Area 1 has very dense deposits of shellfish, and despite only reaching a maximum depth of $70 \mathrm{~cm}$ in this area, more than $109 \mathrm{~kg}$ of shell was recovered. A second season of excavation in 2000 recovered more than $50 \mathrm{~kg}$ of shell for each $1 \mathrm{~m}$ square excavated in Area 2. These samples were processed on-site and this assemblage is not discussed further.

\section{Kulu Bay}

The Kulu Bay open site produced a total shell sample of $11.6 \mathrm{~kg}$. As discussed in Chapter 5, the material excavated at Kulu has probably been redeposited and represents multiple prehistoric phases. Nevertheless, the Kulu sample remains interesting in its diversity, although shell preservation is extremely poor. Despite an interpretation of redeposition, it is interesting

Table 20. Total shell sample weights recovered from EPF archaeological sites.

\begin{tabular}{lcc}
\hline Site & Weight (g) rounded to nearest gram & Number of species represented \\
\hline Natunuku & 58,235 & 143 \\
Ugaga (sub-sample) & 17,255 & 121 \\
Malaqereqere & 13,669 & 110 \\
Volivoli II & 6,399 & 107 \\
Votua (first season only) & 109,092 & 100 \\
Kulu & 11,569 & 92 \\
Navatu & 11,034 & 56 \\
Volivoli III & 920 & 29 \\
Qaranioso I & 23 & Selective sample only \\
Qaranioso II & 786 & 23 \\
Tuvu & 21 & 1 \\
\hline
\end{tabular}


to note that there are depth differences in species representation, perhaps indicating multiple redeposition events from several midden sources.

\section{Navatu}

All shell material for Navatu derives from the Trench B excavations, with a total sample weight of just over $11 \mathrm{~kg}$. A complete sequence is represented from the surface to a depth of $260 \mathrm{~cm}$. This maximum depth for shellfish remains within the sample was in the basal Layer 4 deposit but shell from this layer was 'chalky' and did not survive. Molluscan remains are generally sparse and highly fragmentary below $90 \mathrm{~cm}$ depth, and discussion necessarily centres on the shell recovered from Layers 1 and 2. As at Natunuku, the closest coast is mangrove-dominated and this is reflected in the molluscan sample.

\section{Volivoli II and III}

No shell from Volivoli I was analysed, but samples were examined from the Volivoli II and III rock shelters. Volivoli II was the larger of the two samples, with $6.4 \mathrm{~kg}$ of shell, much of which was composed of fragile land-snail remains. The Volivoli III shell sample totalled $920 \mathrm{~g}$, but land-snail remains were absent. While details of the substantial land-snail component in the Volivoli II sample will be discussed in greater detail below, the major question concerning the presence of land snails is whether they represent natural introductions or cultural refuse. Most of the land-snail species in Volivoli II remain unidentified for want of comparative material, but the three major species were identified from comparison with material held at the Netherlands Museum of Natural History (Naturalis) in Leiden.

\section{Malaqereqere}

The Malaqereqere rock shelter excavations yielded a $13.7 \mathrm{~kg}$ sample of molluscan remains, along with plentiful remains of decapod crustacea and echinoderm spines. While the crab remains, including dactyls, chelipeds and fragments of carapace and legs, were not analysed in any detail, initial sorting identified at least 27 different crab taxa. The absence of reference material precluded further serious analysis. It should also be noted that the abundance of crab holes through the Malaqereqere deposits (see Chapter 5) makes it likely that at least some of the crab remains relate to post-depositional disturbance, rather than being evidence of prehistoric subsistence.

\section{Ugaga}

The large shell sample from the Ugaga site corresponds to the scale of excavations conducted at the site (see Chapter 5). Although total weights for the shell sample were not taken, it is safe to say the Ugaga sample is the largest within this project. For the sake of practicality, the shell was sub-sampled, with a total of $17.26 \mathrm{~kg}$ studied. This total represents all excavated shell from squares -A13, C12, D12, I5 and P10, with C12 and D12 being contiguous squares. As outlined in Chapter 5, squares -A13, C12 and D12 were excavated to below cultural levels to ensure the base of the cultural layer had been reached.

\section{Qaranioso I and II}

As outlined in Chapter 5, excavations at Qaranioso I yielded sparse molluscan remains, with the presence of Anadara and Turbo being noted on site. Only two fragments of shell were retained from these excavations: a fragment of unidentified Strombus sp. and a single Batissa violacea valve. This being the case, the shell sample from this site will not be discussed further. Qaranioso II yielded $786 \mathrm{~g}$ of shell, which seems to be a selective sample. Five fragments of unidentified crab were also present in the sample. 


\section{Tuvu}

Only four fragments of shell, all deriving from the freshwater bivalve Batissa violacea, were recovered from the excavations at Tuvu. Whether these fragments represent subsistence refuse, discarded expedient tools, or both is unclear. Due to the small sample size, this site will not be discussed further.

\section{Methodology and approach}

The level and extent of identifications were considered important for this study, as ecological differences within families and even genera can affect overall interpretations of human gathering practices. Shells were identified using the personal collection of the author, as well as a range of literature sources, including Cernohorsky (1972, 1978), Abbot and Dance (1982), Hinton (1972), Dance (1977), Kira (1965) and Habe (1964). All shells and shell fragments were identified to the lowest possible taxonomic level. However, care was also taken not to overidentify, so that where a fragment itself only had defining characteristics to genus level, it was not assumed that this was part of a dominant species group already identified within the sample. For example, although Lambis lambis was the only species from genus Lambis readily identifiable within the samples, fragments that were clearly genus Lambis but, due to factors such as size or condition, did not carry specific diagnostic traits of Lambis lambis, were only identified to genus level. This was done so as to record ambiguities within the datasets and to minimise methodological assumptions.

An effort was made to identify all shell within the samples, with no assumptions made about the size or condition of the fragment or assumed 'edibility' of the species. Given that the interest was in the range of species collected rather than establishing economic species per $s e$, even species represented only by a single individual were not assumed at the outset to be unimportant or incidental. From a gathering-strategy perspective, even specimens collected secondarily or unintentionally can contribute to an understanding of how gatherers interacted with the environment. In addition, analysis of anything less than every shell in the sample would necessarily prohibit questions regarding whether a gathering strategy was fine or coarse grained.

Three modes of quantification were used for all samples: minimum number of individuals (MNI); number of identified specimens present (NISP) and shell weights. There has been considerable discussion in the literature regarding the relative merits of MNI and NISP techniques (e.g. Mason et al. 1998, 2000; Claassen 2000; Glassow 2000), with a number of important issues raised. NISP is essentially a fragment count of all identifiable pieces of shell, regardless of size or completeness. Thus, issues attached to this quantification method include differential fragmentation between taxa caused by varying degrees of shell robustness, meatextraction techniques applied to particular taxa, fragmentation associated with shell reduction for artefact production, and variable responses to the action of taphonomic processes.

In short, differences between the gross abundance of fragments of identified taxa may mean a number of things. The MNI technique overcomes these issues by counting a single, non-repetitive element consistently throughout a site or stratigraphic layer. The single major problem with MNI quantification - as outlined by Grayson (1984:29-49) - is termed 'division in aggregates'. This applies when arbitrary spits are treated as stratigraphic units by the analyst, and the consistently counted element selected is different between spits, which can serve to inflate counts. For example, if nine spires and four apertures of a Turbo setosus are counted in one spit, and two spires and eight apertures in the next spit, the MNI is not 17 unless these two 
spits represent separate stratigraphic units. If the division between spits is simply arbitrary, the MNI will be 12 on the basis of the higher aperture count.

With fewer parts, the 'division into aggregates' argument is less of an issue with molluscan shell than it is with the quantification of vertebrate faunas, but it is nevertheless desirable to quantify within stratigraphic units. In the assemblages discussed here, details of stratigraphy were not always known at the time of analysis. Thus, quantified elements for particular species remained constant throughout the analysis of shell from each site. In choosing elements for counting, a number of factors were taken into account. For gastropods, apertures tend to be more identifiable than spires, thus for the majority of gastropods, MNI counts refer to aperture frequencies. However, if assemblages are highly fragmented, apertures are frequently broken. In light of this, whole apertures did not form the basis of quantification, but rather the sturdy inner edge of the aperture that represents the anterior portion of the columella. For bivalves, both left and right hinges were counted, and the higher number was taken for either stratigraphic units (where known), or the entire assemblage (where stratigraphic units were unknown). This approach to MNI could well have resulted in the underestimate of abundance, but cannot have overestimated species abundance.

NISP counts were also made for a variety of reasons. Firstly, species represented by one or a few fragments may be simply reduced to 'present' within MNI counts - particularly if only body fragments are present, or there are otherwise few or no easily countable elements. Secondly, the comparison of MNI and NISP totals can give clear insights into differential fragmentation between taxa. If specimens are whole, ratios will be 1:1 for gastropods and 1:2 for bivalves. However, high levels of fragmentation will result in a high NISP count relative to the MNI count. Such situations may point to deliberate cultural fragmentation of particular taxa, related to processes such as meat extraction or shell working.

Quantification by weight is problematic with shell for two main reasons. The first is that shell robusticity is not necessarily tied either to shell size or meat weight. Thus, some large meaty molluscs (e.g. Tonna perdix) have very frail shells, and smaller shells (e.g. Drupa morum, Cantharus undosus) may be robust and relatively heavy. Secondly, processes such as burning and leaching can drastically reduce the weight of a shell. Although weights have been taken for all taxa/spit categories here, the only weight values discussed are total assemblage weights relative to each other, and even these should be treated with some caution.

For all assemblages, condition of the shell was noted. This not only relates to the condition of preservation, but to human variables such as burning and observed meat-extraction patterns. It further includes the alteration of shells by natural processes. Any shells that were observed to be introduced to deposits post-mortem, through the recording of indicators such as beachrolling and sponge-boring and epibiont adhesions (such as worm-casts and barnacles) on the inner surfaces, were excluded from quantifications.

Given the geographic spread of the samples under consideration here, investigating issues of change over time seemed unviable, although where clearly stratified sequences exist (e.g. Volivoli II), such issues receive consideration. Rather, the overall thrust of the questioning here relates to how ancient Fijians - at different times and in different locales - interacted with the aquatic environment through shellfish gathering. It has often been assumed that shell-gathering practices target the largest individuals or species (e.g. Kress 2000: 295-296; see Allen 2003 for a general discussion). While there have been occasions where this has been demonstrated (e.g. Anderson 1981), results have also sometimes diverged from this expectation (e.g. Szabó 1999). I am reluctant to follow Allen's (2003) suggestion that a prey-choice model (sensu Broughton 
1999) be applied at the outset, as experience suggests that assumptions often lead to an analytical, or indeed on-site sampling, bias where smaller or seemingly insignificant taxa are sidelined or ignored altogether.

Taking a different starting point, the principal question asked here of each assemblage is how ancient Fijians exploited molluscan resources, without underlying assumptions or expectations as to what is expected according to a particular model. Is there a noticeable focus on particular taxa, size or age classes? Do these patterns change over time or between collecting environments? Are multiple niches being exploited simultaneously? Through an analysis of the samples treated here, the aim is to examine the selectiveness or otherwise of Fijian shellfishgathering strategies.

\section{Results}

The results of shell analysis for each site will be presented first, as many have their own particular issues and complexities. Following this, the results will be considered in the discussion.

\section{Natunuku}

As outlined above, the discussion of molluscan remains recovered from the Natunuku site relies largely on results from the major Trench 3 excavations. Trench 3 yielded a total of 5978 individuals (MNI) across 109 different molluscan species. A further 34 species were identified from areas other than Trench 3, bringing the total number of species for Natunuku to 143 . Figure 85 shows the spread of all taxa represented by 20 or more individuals (MNI) within the Trench 3 sample. While Anadara antiquata is dominant, both Gafrarium tumidum and the small upper-intertidal rocky shore gastropod Planaxis sulcatus are strongly represented. A range of hard and soft-shore species are represented in much lower numbers. The spread of individuals derived from different niches is shown in Figure 86.

When the results of analysis for the Natunuku molluscan sample were originally published (Szabó 2001), the spread and relative proportions of taxa were interpreted within a framework of 'target species'. These included primary species that were interpreted as being the major focus of interest in gathering forays, secondary species that would be collected if encountered in the search for primary species, and incidental species that were seen as being the 'by-catch' or those species accidentally gathered or introduced into deposits. In light of additional analysis of shell-midden material from Fiji and elsewhere, this remains one of two likely interpretations for the wide diversity of species that contribute to overall assemblages. The other interpretation is that there was very low selectivity in the gathering process. This latter interpretation is now considered more likely, for one reason in particular: in addition to a high level of species diversity, all the Fijian middens studied showed little discrimination as to the size of individuals selected. Thus, even in early sites such as Natunuku where very large individuals of various species are present, juvenile and sub-adult specimens are also a notable component of the assemblage. There appears to be no chronological patterning to size-classes represented, with large and small specimens being taken simultaneously throughout the prehistoric sequence. This is amply demonstrated in Figures 87 and 88, which show the anterior-posterior measurements for all Anadara antiquata and Gafrarium tumidum valves complete along this axis from Trench 3.

When the results of quantification for Trench 3 and the Natunuku site as a whole are compared, it is apparent that there is some level of intra-site variation in the distribution of molluscan taxa (compare Figure 89 with Figure 85). Rocky-shore taxa, such as Saccostrea cucullata, Planaxis sulcatus and Clypeomorus traillii, are better represented in areas outside Trench 3, while, correspondingly, soft-shore taxa are slightly more prevalent in Trench 3. Also, 


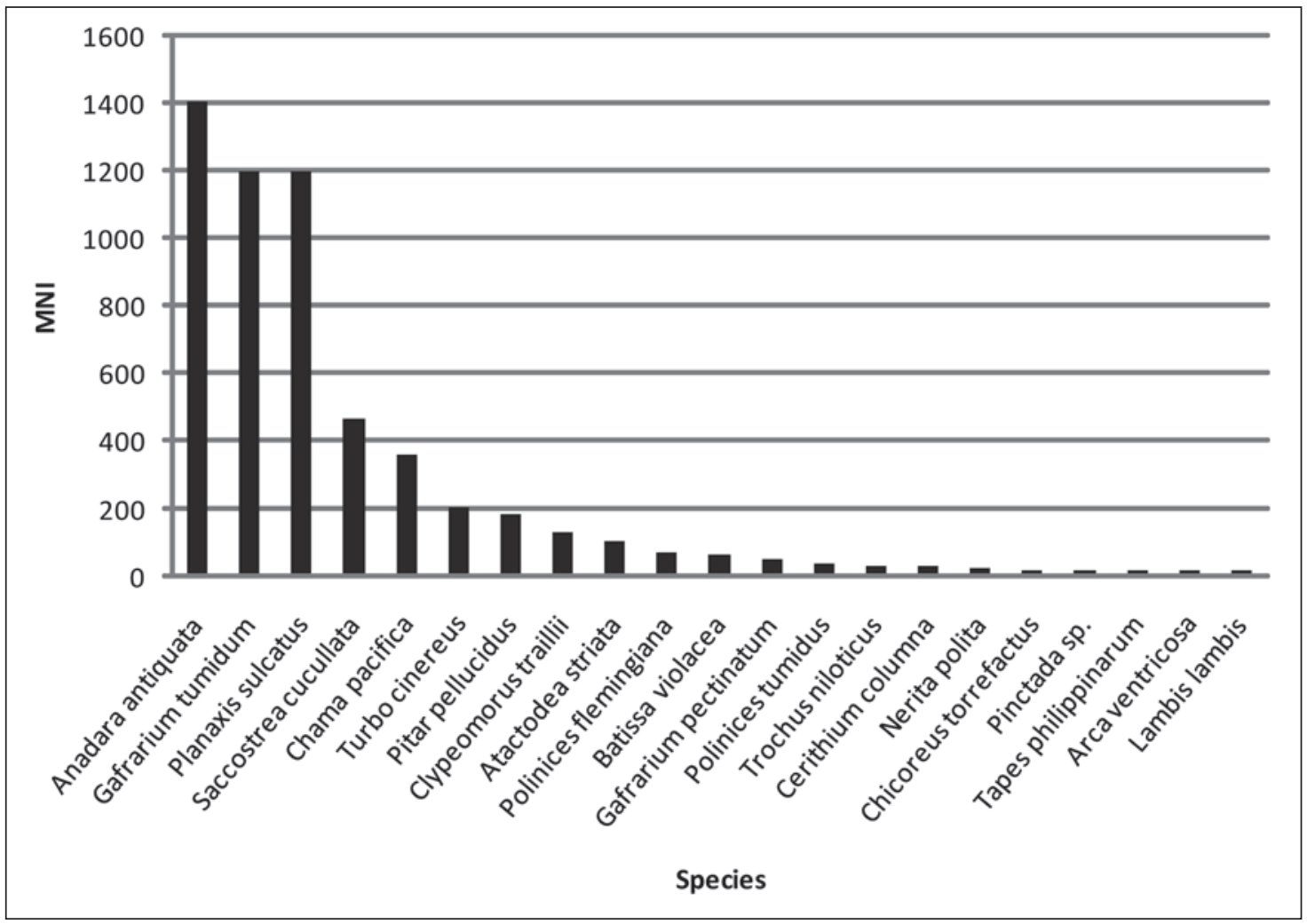

Figure 85. Mollusc species from Natunuku, Trench 3, represented by 20 or more individuals (MNI).

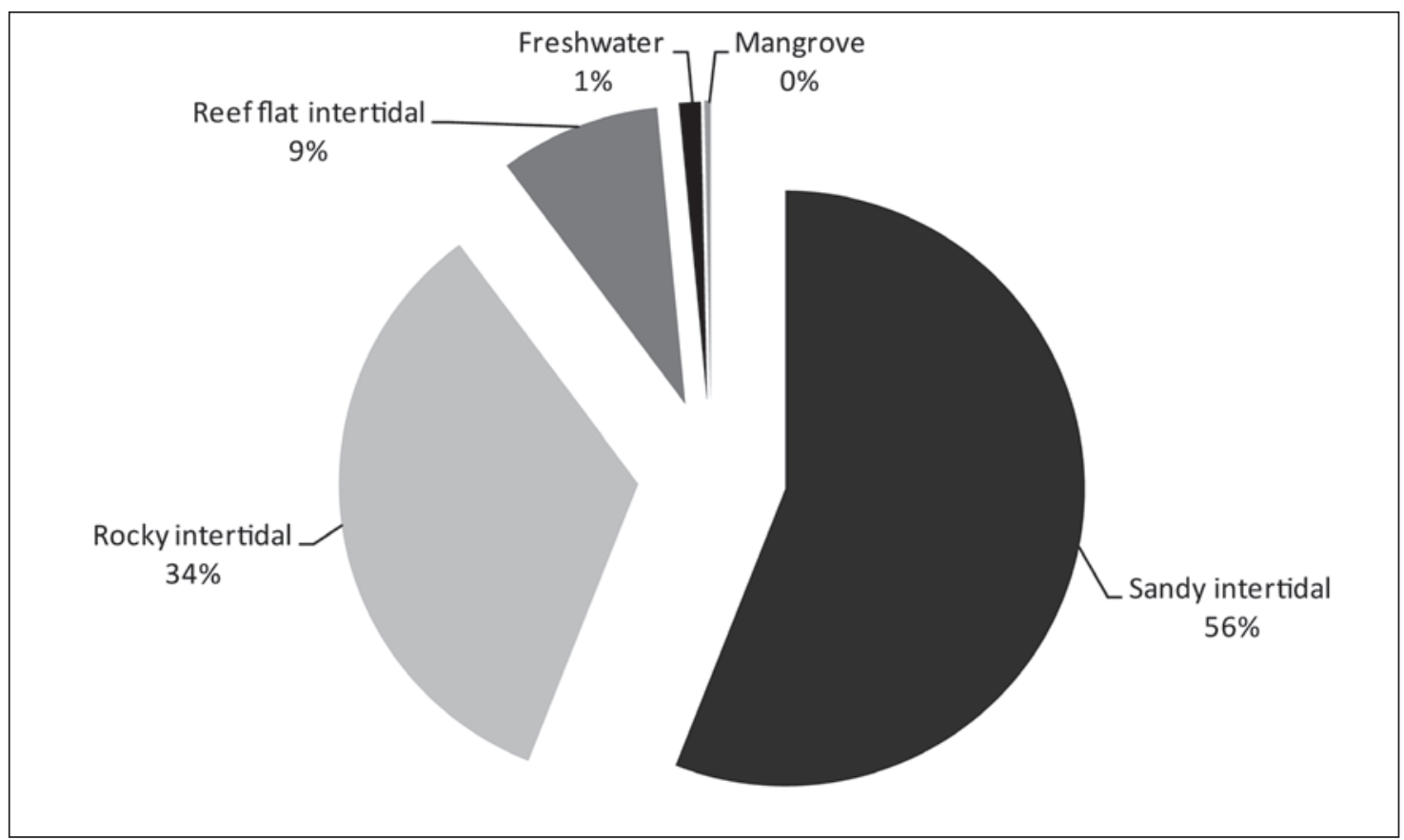

Figure 86. Proportions of different environments represented in the Natunuku shell assemblage as calculated through MNI values. 


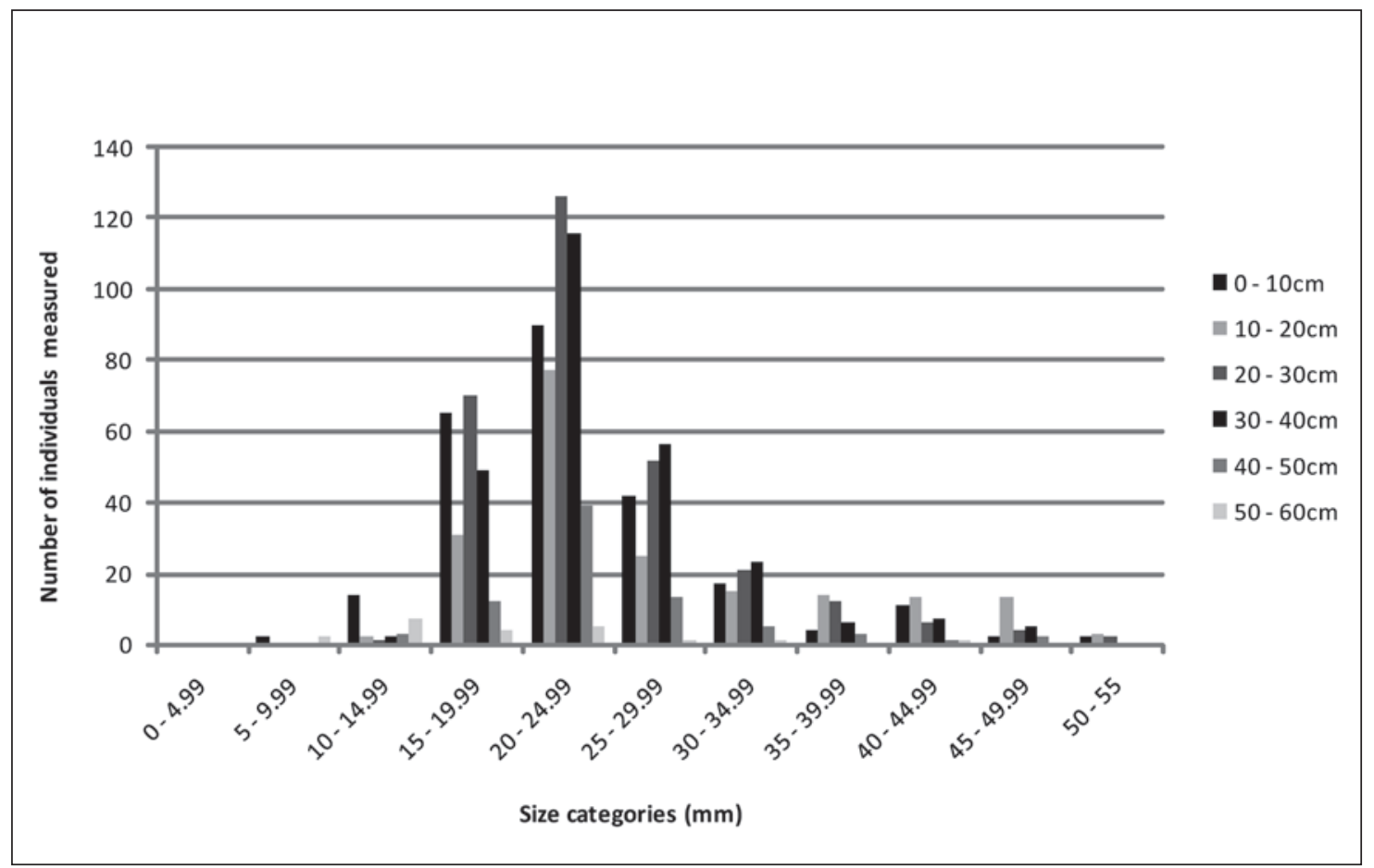

Figure 87. Frequency of various size-classes of Anadara antiquata within the Trench 3 sample from Natunuku.

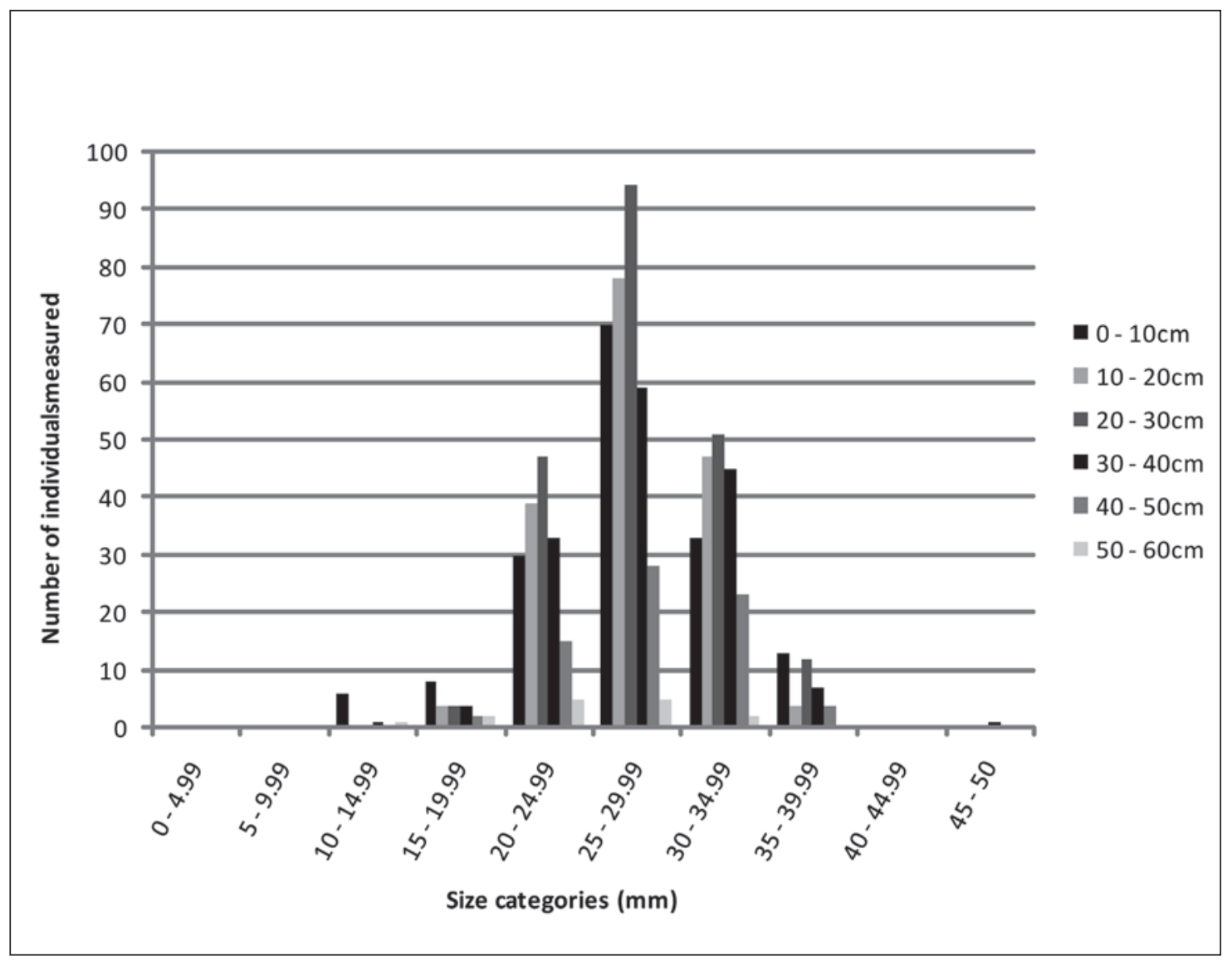

Figure 88. Frequency of various size-classes of Gafrarium tumidum within the Trench 3 sample from Natunuku. 


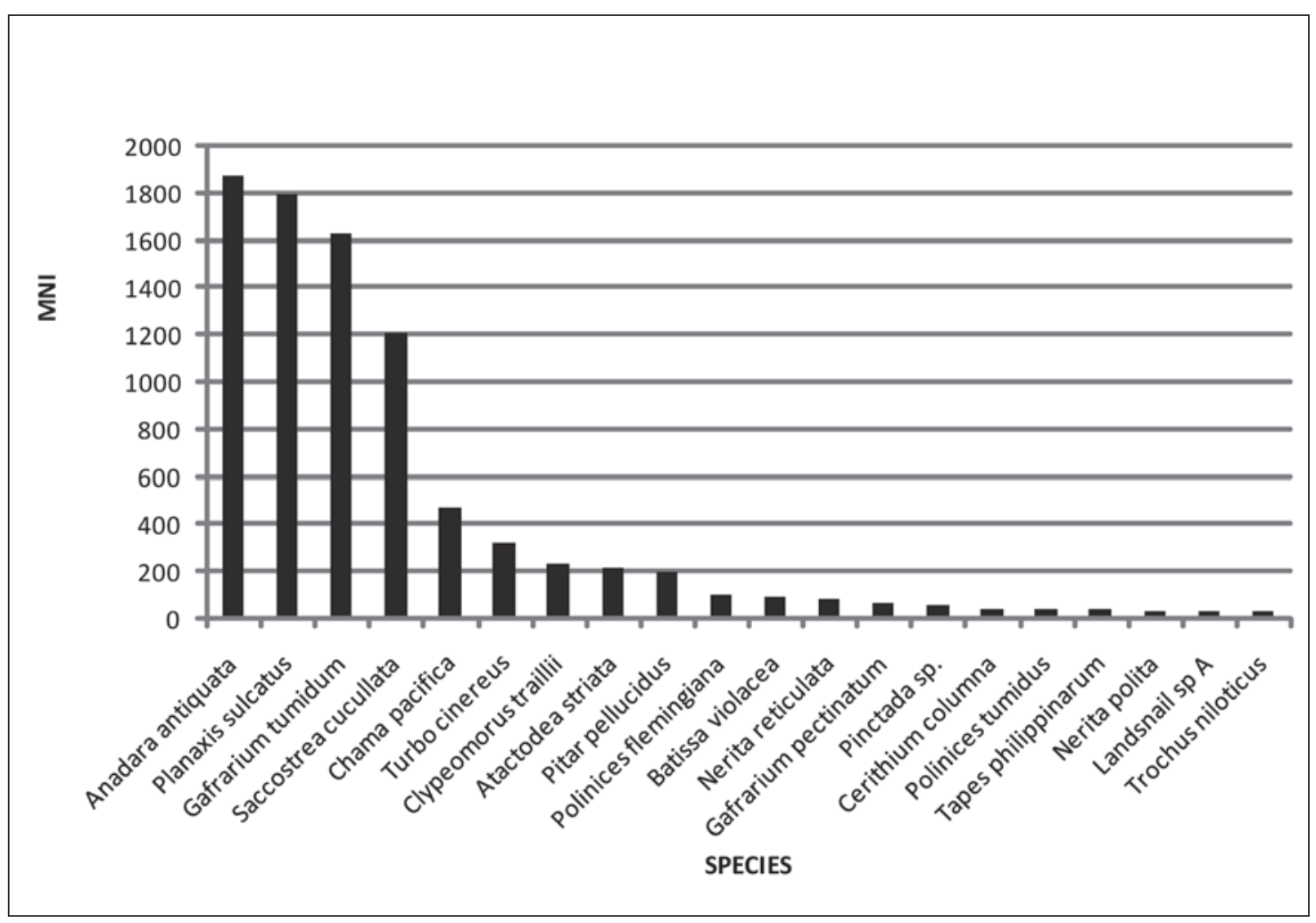

Figure 89. The 20 highest ranking species (MNI) in the complete Natunuku shell sample.

freshwater gastropods, such as neritids within the genus Clithon, and coastal vegetation-dwelling gastropods, such as Cassidula nucleus, are restricted to areas outside Trench 3. The mangrove pearl oysters Melina ephippium and Isognomon sp. are likewise absent from Trench 3. Observations such as these suggest, unsurprisingly, that molluscan remains from different gathering forays are being deposited in different areas of the site, and in all likelihood are being deposited closer to the niches from which they were originally collected. Thus, despite the large size of the Trench 3 sample, it is clear that additional information can be derived from drawing samples from different areas of large sites such as Natunuku.

Votua

The Votua 1996 shell sample contains 4533 individuals (MNI) from a minimum of 100 different molluscan species. Square A1 contained the most shell, with a total of 2297 individuals, with A2 having 1902 individuals and the remaining 334 individuals deriving from TP 1 . The dominant species in all locales is Anadara antiquata, being supplemented by lesser numbers of Turbo chrysostomus and Gafrarium tumidum (see Figure 90). Despite the individual dominance of softshore bivalve species, diverse reef-flat and rocky-shore taxa represented by smaller numbers of individuals combine to make these zones important gathering areas too. Figure 91 shows that the reef-flat intertidal zone contributes $23 \%$ of all individuals, while the rocky shore contributes a further $4 \%$. The freshwater species Batissa violacea and Clithon brevispina $(\mathrm{n}=6)$ are present in low numbers, but nevertheless demonstrate occasional exploitation of freshwater habitats.

There would appear to be little difference in species composition by depth across TP 1, Area 1 and Area 2. The oyster-rich layer noted for the lower reaches of Area 2 (see Chapter 6) is not apparent in the final quantifications for the 1996 sample. If this is the case, it would appear that either human preference or the nature of the littoral zone near the site changed substantially before deposition of the main midden. 


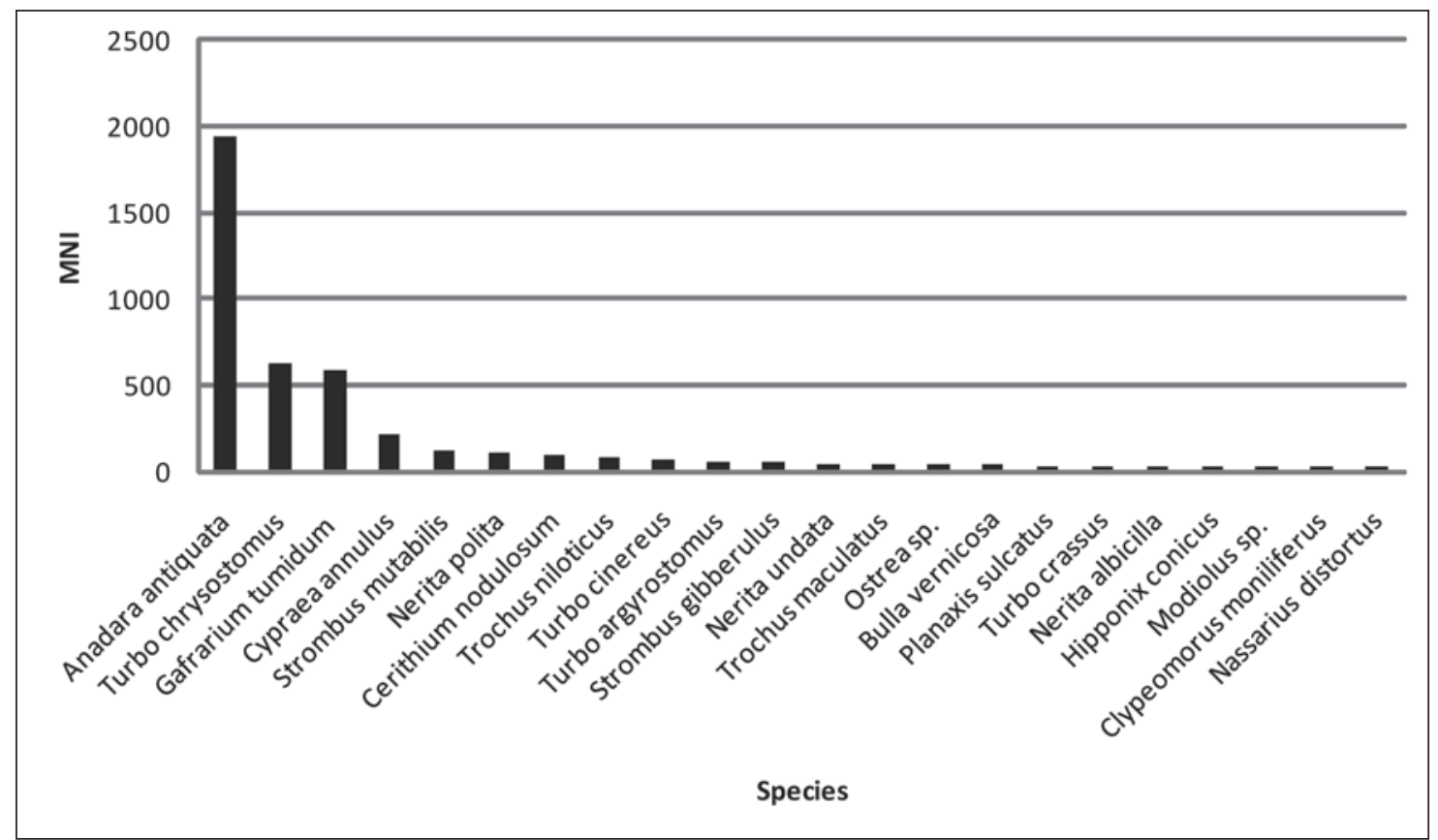

Figure 90. Mollusc species from Votua represented by 20 or more individuals (MNI).

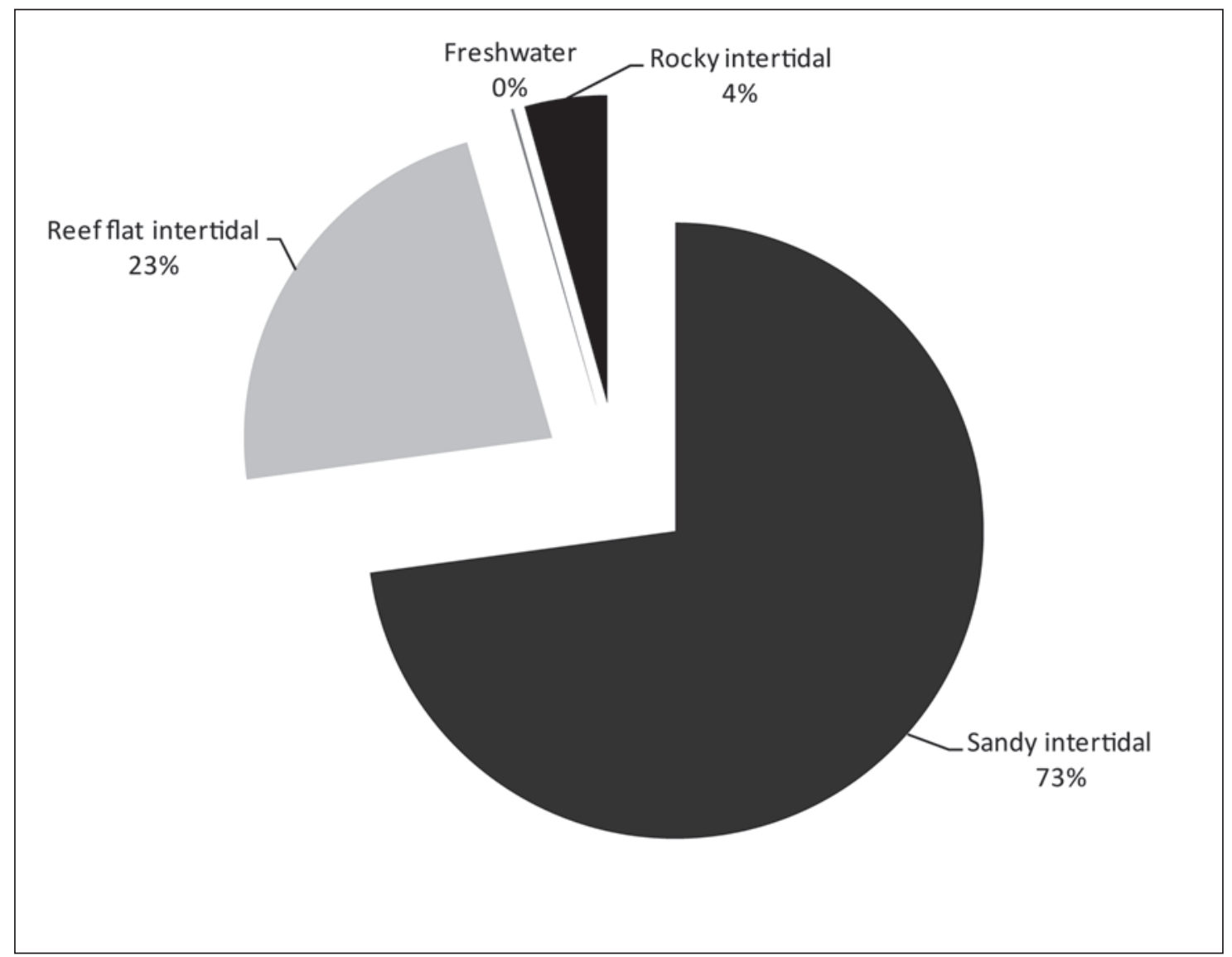

Figure 91. Proportions of different environments represented in the Votua shell assemblage as calculated through MNI values. 


\section{Kulu Bay}

The most noticeable feature of the Kulu assemblage is the diversity of taxa present: 92 species in a total of less than 1000 ( $\mathrm{n}=903 \mathrm{MNI})$ individual specimens. Figure 92 graphs the taxa represented by 10 or more individuals, and it can be seen that no particular taxon dominates. Opercula of various species of Turbo, at least five of which are represented within the Kulu Bay I sample, dominate the assemblage. However, the numbers of opercula $(n=516)$ greatly outnumber the combined MNI for all species of Turbo represented by shells alone ( $\mathrm{n}=114$ ). This may be an issue of preservation, as all shell recovered from Kulu I was chalky and highly deteriorated, although many smaller and frail taxa survive in identifiable condition.

The $160 \mathrm{~cm}$ sequence deriving from Square C11 shows a trend that accords well with on-site observations regarding stratigraphy, but diverges in terms of observations on shell concentrations. Figure 93 shows the abundance by depth of the major species represented within the Kulu Bay assemblage: Turbo spp. opercula, Cerithium nodulosum, Turbo chrysostomus and both left and right valves of the small bivalve Atactodea striata. There are two noticeable peaks in shell frequencies. The first is within Layer 2 from about $40 \mathrm{~cm}$ to $110 \mathrm{~cm}$, in association with animal bone, lithic flakes and fragments of various types of pottery. The second is a smaller peak associated with the sticky clay Layer 3, from around $120 \mathrm{~cm}$, dropping off at $170 \mathrm{~cm}$. Excavation of the latter layer was associated with large Turbo and other shells, but, in fact, only two Turbo spp. shells (one Turbo chrysostomus and one Turbo argyrostomus) were recorded for this layer, as opposed to 29 individuals from medium-large Turbo spp. in Layer 2. There is little difference in the species composition of the two peaks, and the fact that some species (such as the freshwater Batissa violacea) only occur in Layer 2 is just as likely to be a reflection of differential sample size as environmental or behavioural change.

One of the most striking features of the Kulu Bay molluscan assemblage is the diversity of niches from which the sample was drawn. Figure 94 shows that the majority of shellfish

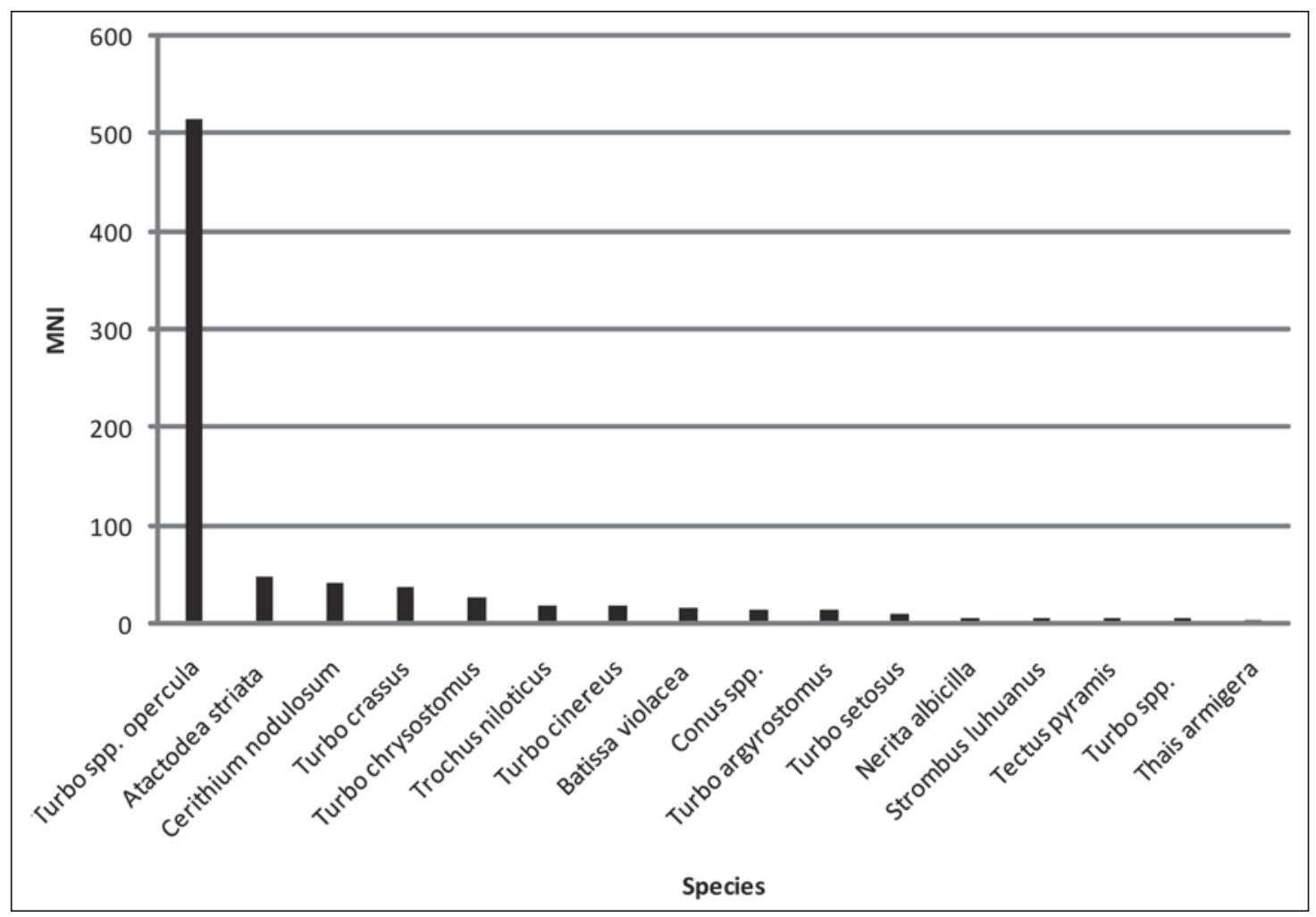

Figure 92. Mollusc species from Kulu Bay 1 represented by 10 or more individuals (MNI). 
represented within the sample derive from either sandy intertidal or hard reef-flat intertidal niches, with a further $9 \%$ being drawn from the rocky upper-shore zone, $4 \%$ from the subtidal rocky zone and $6 \%$ from freshwater habitats. Given the redeposited nature of the Kulu assemblage, it cannot be said whether this diversity in environmental composition reflects similar diversity within the original donor assemblage, or whether it represents a composite of different deposits focused on distinct niches.

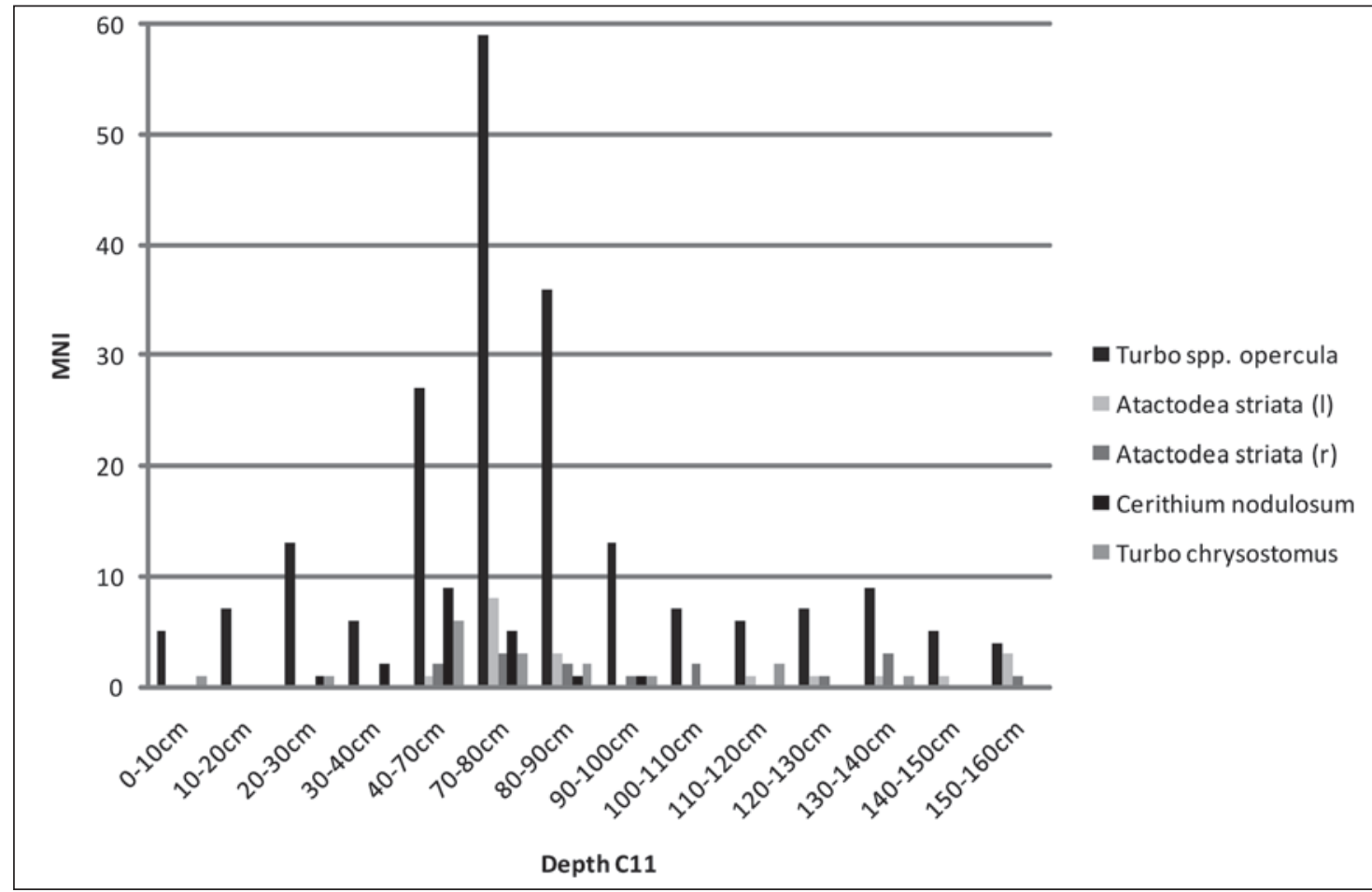

Figure 93. Distributions of major molluscan taxa by depth within Square C11, Kulu Bay 1.

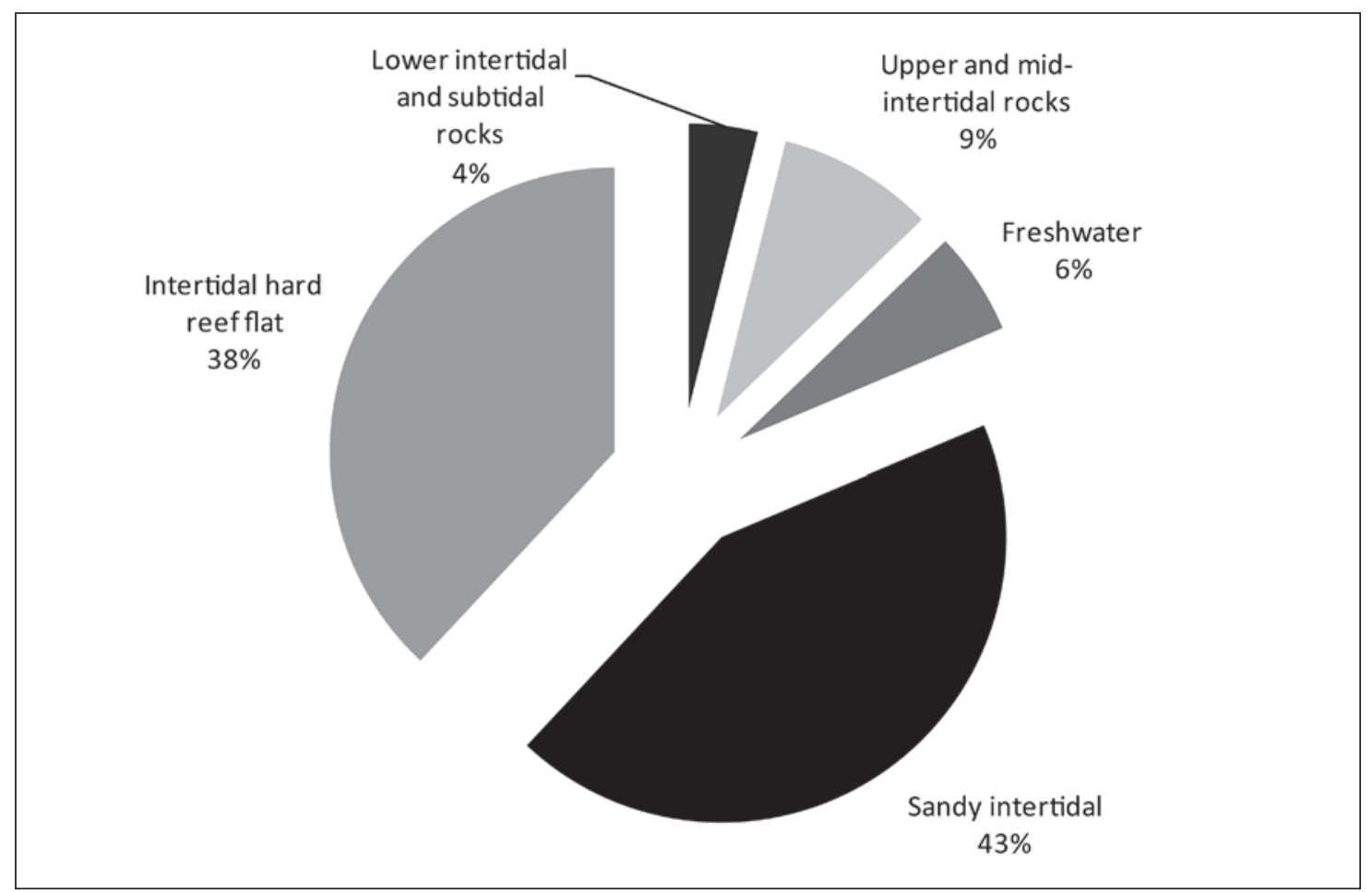

Figure 94. Proportions of different environments represented in the Kulu shell assemblage as calculated through MNI values. 


\section{Navatu}

As mentioned above, shell was sparse below a depth of $90 \mathrm{~cm}$, meaning that the bulk of Navatu molluscan remains relate to Layers 1 and 2. These have been treated as one sample in light of various problems to do with separating the two analytically. Species represented by five or more individuals are shown in Figure 95. With only 556 individuals (MNI) within the Navatu sample, it is questionable how much can be concluded from the contribution of various species relative to each other. Nevertheless, the dominance of bivalves is noteworthy, with most deriving from the soft-shore zone (e.g. Gafrarium tumidum, Anadara antiquata and Fragum unedo), supplemented by species from the rocky intertidal and subtidal niches (e.g. Saccostrea cucullata, Chama iostoma). Clean reef environments are not especially well represented, with four Tridacna spp. specimens (one Tridacna maxima and one Tridacna squamosa, one Tridacna gigas and one specimen identifiable only to genus level) and only two Trochus niloticus specimens. Apart from the rocky-shore-dwelling Turbo cinereus, there are no turbinid shells. However, despite a paucity of molluscs deriving from the clean reef-flat environment, the gathering spectrum is far from homogenously silty sand. Figure 96 shows that $68 \%$ of individuals derive from soft intertidal substrates, grading from muddy to weedy sand. Of the remaining $32 \%, 25 \%$ come from rocky substrates, with a further $4 \%$ from clean reef flats and $2 \%$ from freshwater environments. The freshwater component is not composed simply of Batissa violacea valves, which are frequently transported as expedient tools, but consists also of the gastropods Melanoides tuberculata and an unidentified species of freshwater Neritidae (Neritina sp.).

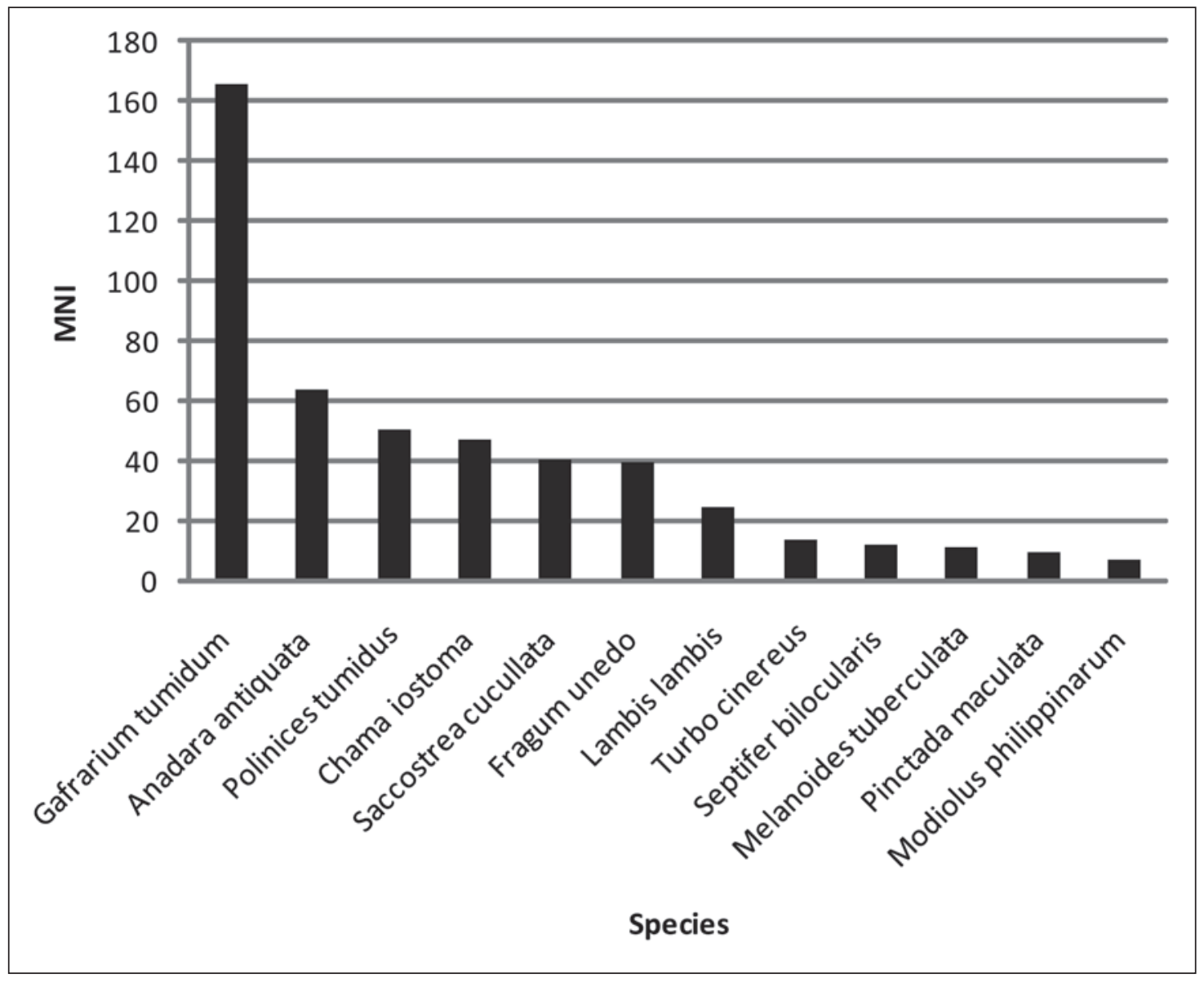

Figure 95. Mollusc species at Navatu represented by five or more individuals (MNI). 


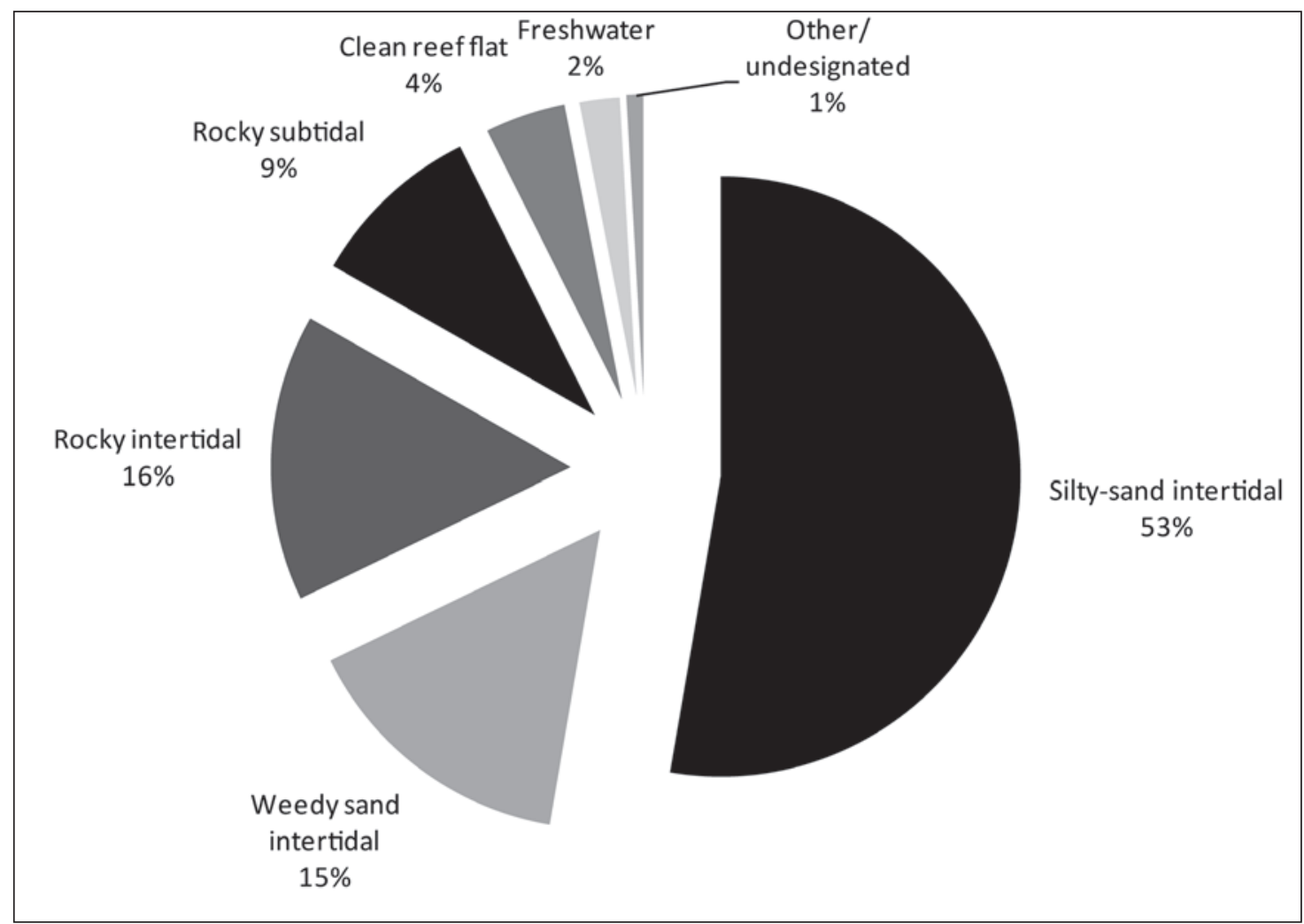

Figure 96. Proportions of different environments represented in the Navatu shell assemblage as calculated through MNI values.

\section{Volivoli II and III}

The Volivoli II shell assemblage is one of the more intriguing of the EPF sites, not least for its terrestrial snail component. The well-stratified nature of the sample, coupled with clear differences in molluscan composition within this stratigraphy, means that more questions can viably be posed of the Volivoli II assemblage than of many of the open middens.

Molluscan shell was recovered to a depth of $130 \mathrm{~cm}$, which represents the base of the shelter. However, as observed in Chapter 5, cultural material largely disappears at $80 \mathrm{~cm}$ depth. This discrepancy between the molluscan vertical spread and cultural stratigraphy makes sense only when the shell component is scrutinised in greater detail. Volivoli II is the only site excavated as part of this project that has a sizeable terrestrial-snail component. Land snails occur throughout the sedimentary sequence, but distinct changes can be observed stratigraphically. There is only one land-snail species, Naninia pfeifferi, which occurs in numbers throughout the cultural layers. Indeed, it is the most abundant species from the surface to a depth of $70 \mathrm{~cm}$. Within the $70-80$ $\mathrm{cm}$ spit a distinct change is seen, with $N$. pfeifferi falling off, and disappearing completely below a depth of $90 \mathrm{~cm}$. In its stead, a group of other terrestrial snail taxa appears, dominated by two other ariophantid snails: Naninia cf. ornata and an unidentified species of Naninia. Land-snail abundances by depth are shown in Figure 97.

The land-snail assemblage from below $80 \mathrm{~cm}$ depth is composed of a variety of species, including some very small $(>1 \mathrm{~cm})$ taxa, and represents a natural-death assemblage, in line with the stratigraphic distribution of cultural materials in the site. The dominance of $N$. pfeifferi above $80 \mathrm{~cm}$ presents another issue. This species is not represented in the natural-death assemblage from $90-130 \mathrm{~cm}$ depth, implying it was not part of the land-snail community located in close proximity to the site before human occupation. While its sudden appearance may be to do with vegetational change around the rock-shelter area, its dominance over culturally associated 
taxa and the virtual disappearance of all other taxa found in the lowest layer of the site suggest another explanation.

It has rarely been considered that terrestrial snails can be food resources, and indeed, given the low occurrences of medium-large land snails in coastal Pacific sites, there is little reason why they generally should be considered. Inland sites present different resource opportunities, and a local abundance of reasonably sized land snails may, in these circumstances, appear an attractive resource. With regards to Volivoli II, if land snails were entirely self-introduced, one would expect to see a cross-section of the local land-snail population within the site, including various taxa, size and age classes. This is, indeed, what is present towards the base of the site. However, it is not what is present above $80 \mathrm{~cm}$. In sum, the presence of $N$. pfeifferi in the upper $80 \mathrm{~cm}$ to the exclusion of other land snails and this species' dominance over marine taxa point to human agency (see Figure 98). The fact that the lower levels of the deposit do suggest that $N$. pfeifferi was a major taxon in the natural land-snail fauna around the site supports the view that the species was a resource deliberately gathered by humans.

Looking at the rest of the cultural molluscan assemblage, Turbo spp. opercula are abundant $(\mathrm{n}=496)$, and as at Kulu Bay, occur in considerably greater numbers than remains of the shells themselves $(\mathrm{n}=80)$. While this is feasibly related to taphonomic issues and loss of shell fragments, unlike Kulu Bay, the preservation of shell remains at Volivoli II is excellent. The difference in Turbo spp. shell and opercula representation is more likely due to the distance of the Volivoli II shelter from the coast (ca. $1.5 \mathrm{~km}$ ). Turbo spp. shells are relatively heavy and bulky, and if the shells were processed at or near the point of collection, and only the animal and adherent operculum transported back to the site, one would expect a refuse pattern such as that witnessed at Volivoli II. If this interpretation is correct, we might expect other clean reef-flat species with bulky or heavy shells to have been processed in a similar way. It is possible that heavy species such as Trochus niloticus $(\mathrm{n}=12)$ and Tridacna spp. $(\mathrm{n}=1)$ are under-represented at Volivoli II.

It is clear that environments other than clean reef flats and terrestrial locales were being exploited by the inhabitants of Volivoli II. The freshwater bivalve Batissa violacea occurs in relatively high numbers $(\mathrm{n}=297)$, and is supplemented by various fresh/brackish-water neritids

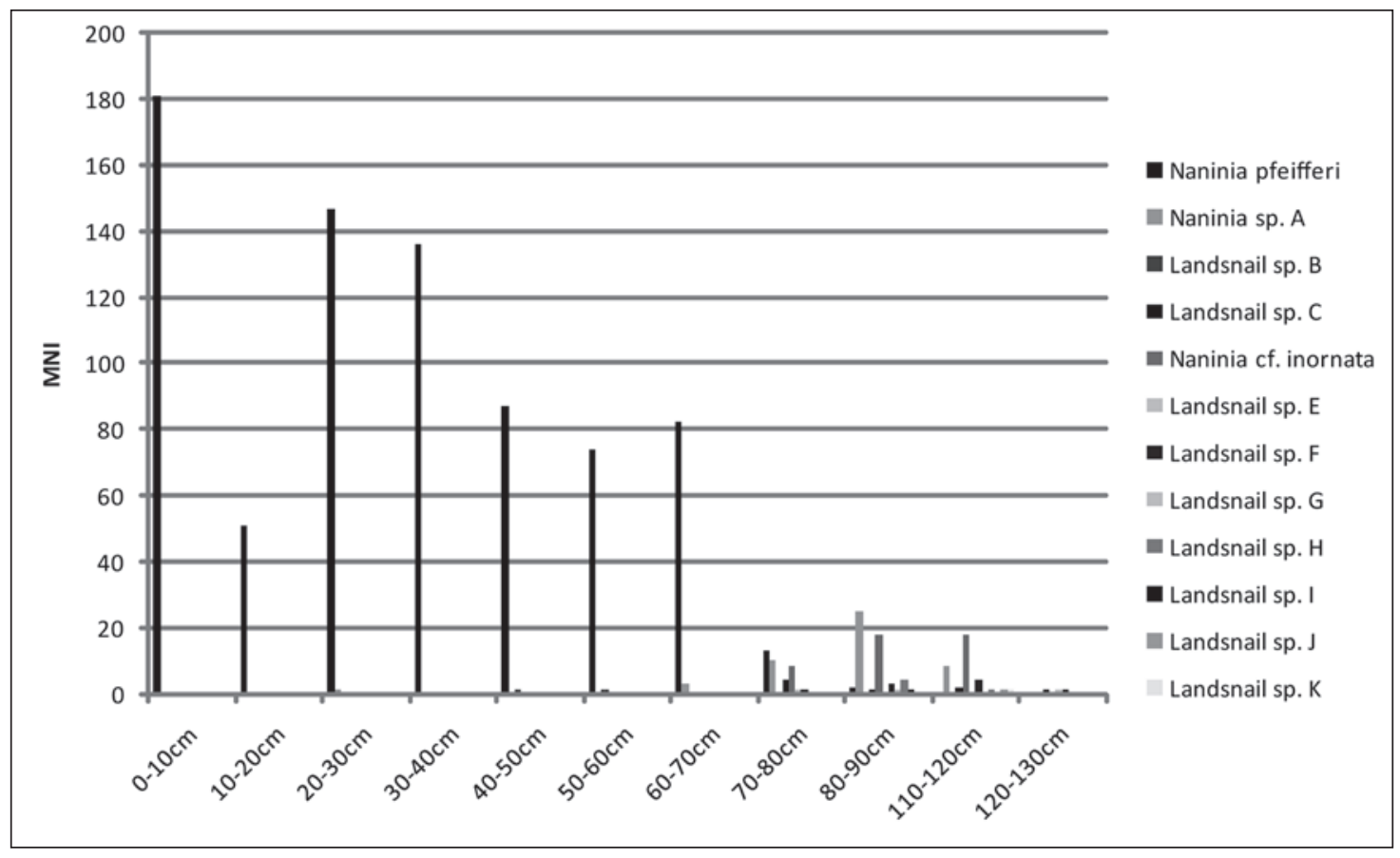

Figure 97. Land-snail abundances (MNI) by depth at Volivoli II. 
(Neritina turrita, Neritodryas dubia), freshwater thiarids (Melanoides tuberculata and Thiara sp.) and an unidentified freshwater bivalve. The lack of clearly mangrove/estuarine-associated bivalves and gastropods suggests that such freshwater environments were not located in the immediate vicinity of the coast.

Figure 99 shows the proportions of the overall mollusc assemblage that derive from various environmental niches. In addition to the terrestrial, reef-flat intertidal and freshwater environments already discussed, $27 \%$ derive from weedy-sand environments. There is a strong focus on gastropods, and in particular Strombus mutabilis ( $\mathrm{n}=190)$, supplemented by smaller contributions from Strombus gibberulus gibbosus $(\mathrm{n}=39)$, Tellina palatum $(\mathrm{n}=48)$ and various cypraeids, cerithids and naticids.

As mentioned above, the Volivoli III molluscan sample is much smaller, reflecting the lower frequency of shell in these deposits. Unlike Volivoli II, there were no land snails identified within the Volivoli III sample, although in terms of the marine component, there are strong similarities between the two shelters. Twenty-nine species are represented, with the most common species being Strombus mutabilis $(\mathrm{n}=39)$, followed by the freshwater bivalve Batissa violacea $(\mathrm{n}=16)$. Species represented by more than a single individual are graphed in Figure 100. The absence of land snails from Volivoli III reinforces the interpretation of a cultural introduction for Volivoli II, while the exploitation of freshwater, reef-intertidal and weedy-sand environments remains constant (see Figure 101).

Aside from the terrestrial-snail component, the only notable difference between the Volivoli II and III molluscan shell samples is the predominance of Turbo spp. shells over opercula at Volivoli III. It is possible that the smaller volumes of shell transported to Volivoli III made feasible the transport of whole unprocessed shells, rather than simply the flesh and opercula.

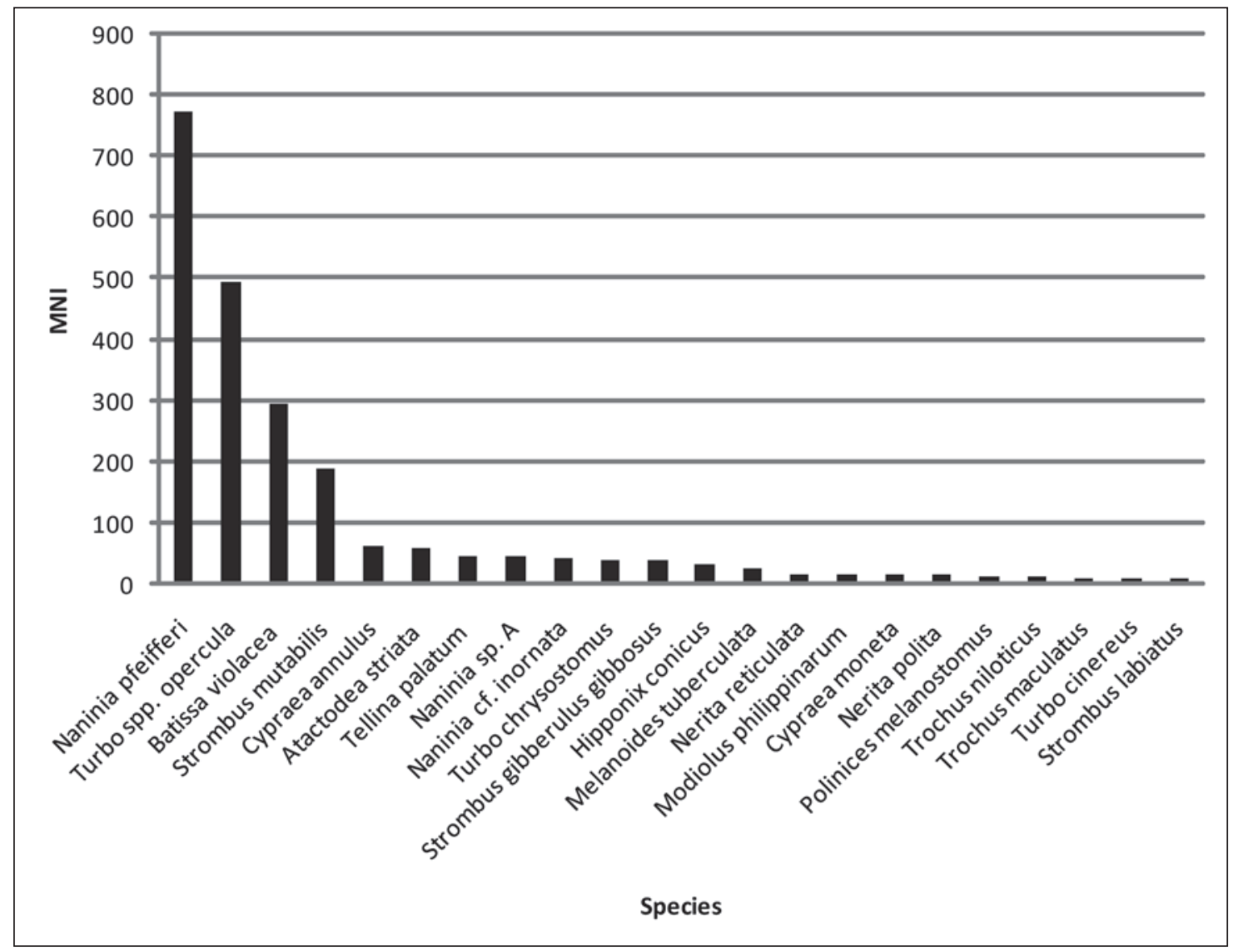

Figure 98. Molluscan taxa represented by 10 or more individuals at Volivoli Il. 


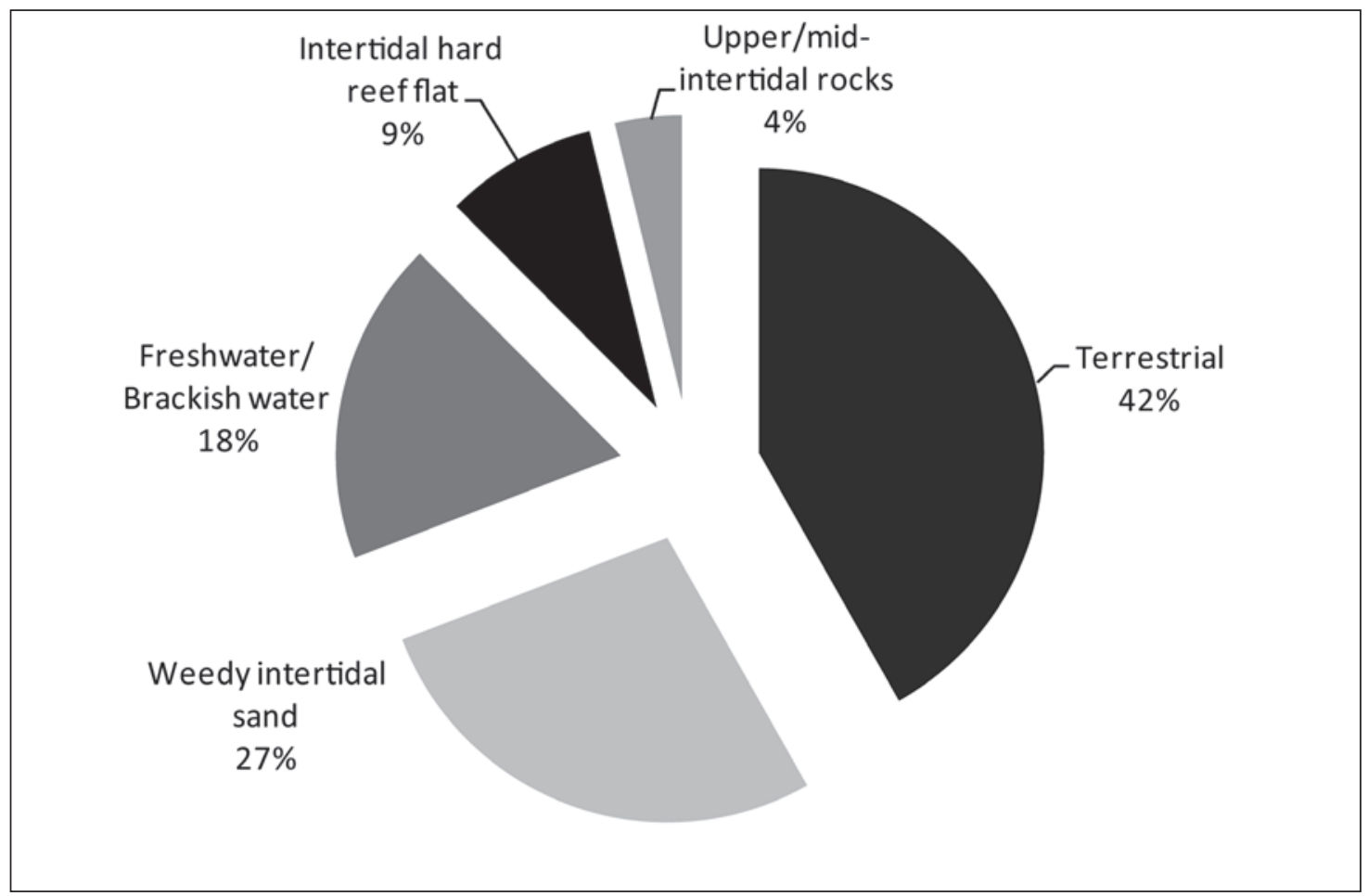

Figure 99. Proportions of different environments represented in the Volivoli ll shell assemblage as calculated through MNI values. The only land snail included within these calculations is Naninia pfeifferi. Opercula values for Turbo spp. and Nerita spp. have been omitted as, without species information, ecological attribution is not feasible.

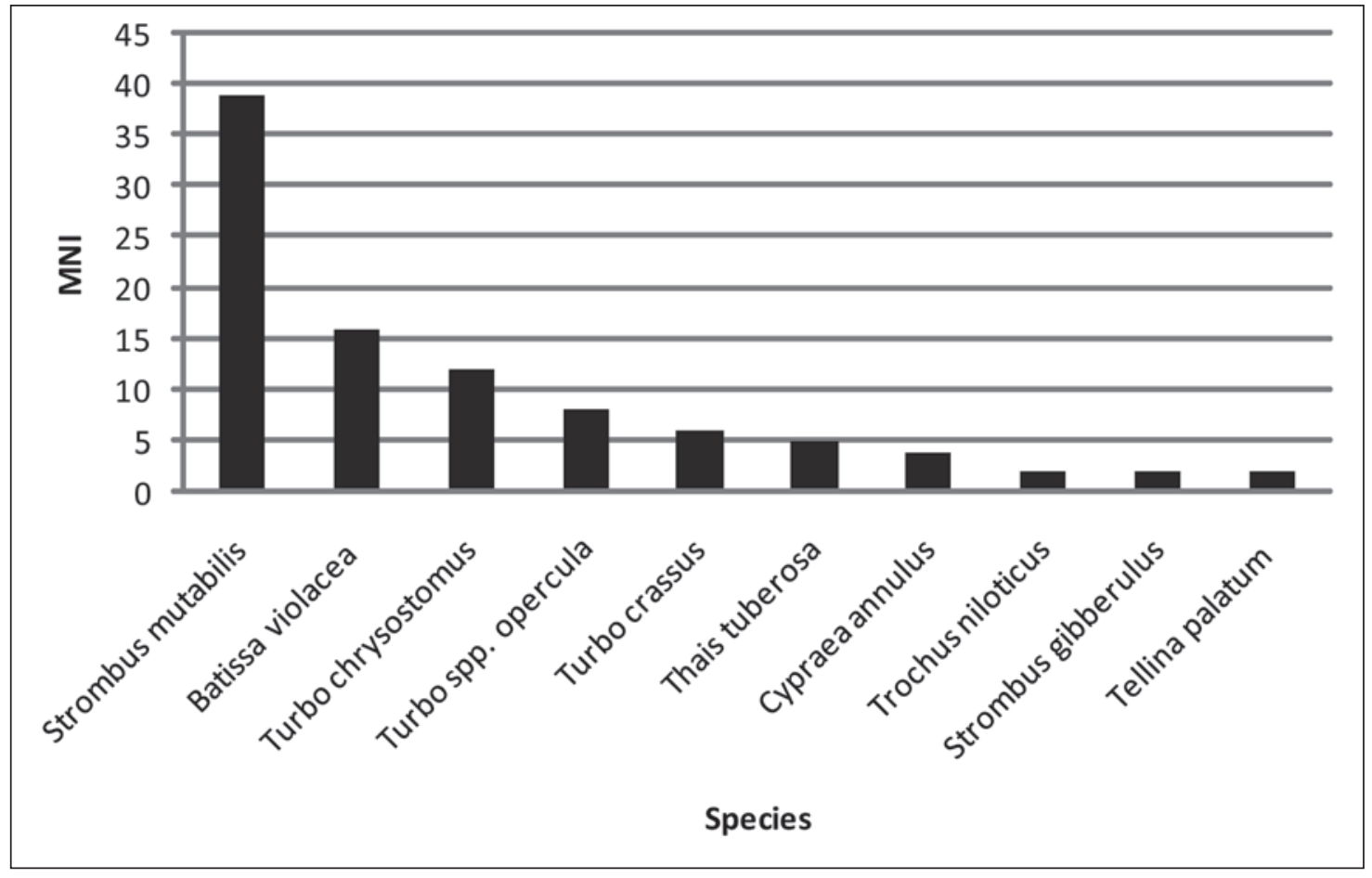

Figure 100. Mollusc species from Volivoli III represented by more than one individual (MNI). 


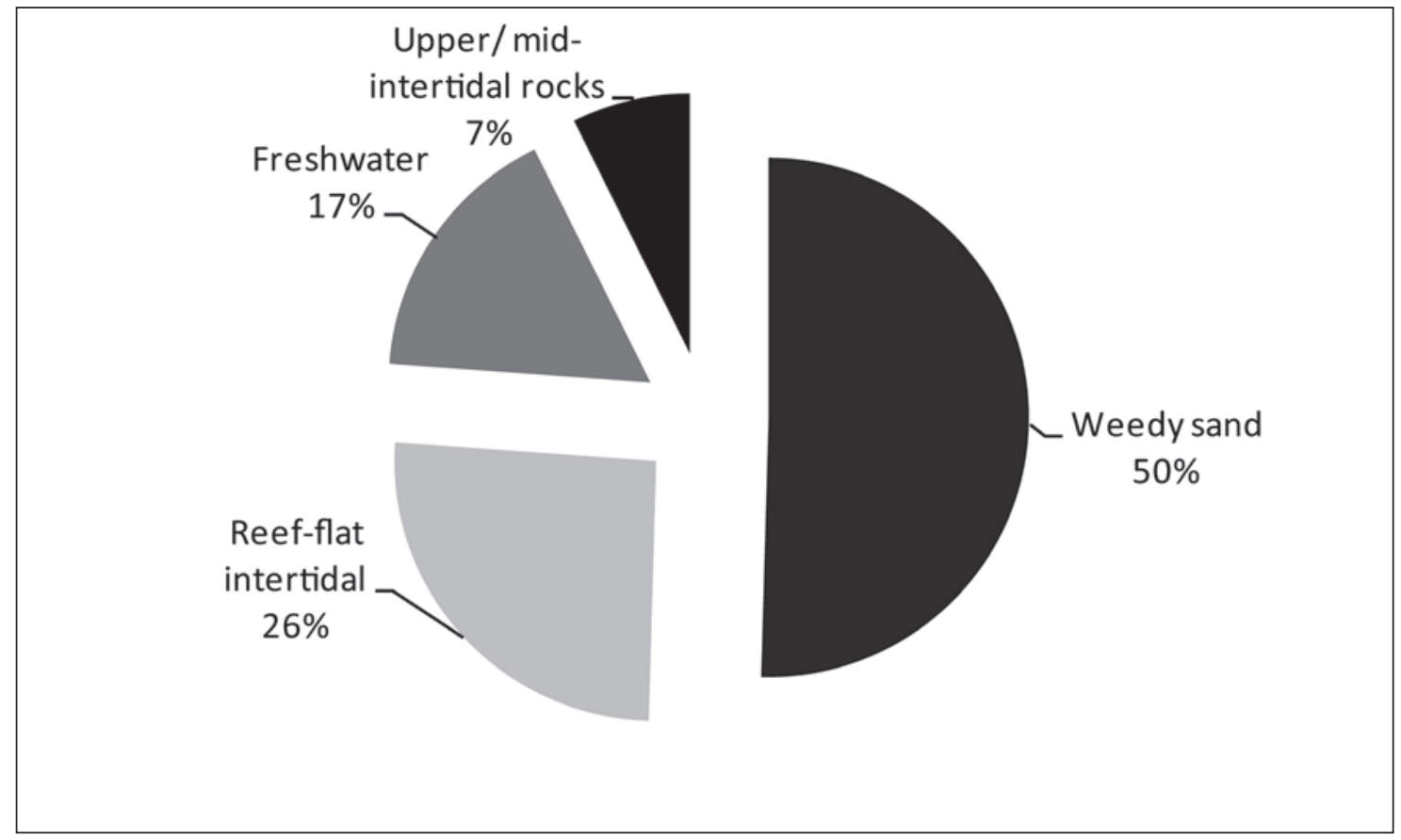

Figure 101. Proportions of different environments represented in the Volivoli III shell assemblage as calculated through MNI values. Turbo spp. operculum values have been omitted from these calculations so as not to inflate the importance of Turbo.

\section{Malaqereqere}

The shell sample from Malaqereqere is relatively large and diverse, with a total of 6071 individuals (MNI), deriving from at least 110 species. This latter total does not include specimens identified only to genus level, except where such fragments are the only one/s identified for that genus. As outlined in Chapter 5, the Malaqereqere shelter had a complex stratigraphy in which five major layers were recognised. The difficulty in dealing with the shell sample is that it was retrieved according to $10 \mathrm{~cm}$ spits and, given that most layer divisions fall halfway between spits, the sample cannot be reconciled back into layers. Despite these difficulties, an investigation of change in taxonomic frequency per spit offers some insight into changing gathering patterns. These are discussed further below.

Malaqereqere follows the pattern seen in Volivoli II and Kulu Bay, whereby Turbo spp. opercula dramatically outnumber the combined total of individual shells identified within the genus (see Figure 102). This does not necessarily represent a focus on intertidal reef-flat exploitation, given the dominance of the rocky-shore Turbo cinereus over reef-intertidal taxa such as Turbo setosus, T. chrysostomus and T. crassus in the assemblage. Indeed, the most wellrepresented taxa give some idea as to the overall pattern of niche exploitation by Malaqereqere shellfish gatherers (see Figure 103). Strombus mutabilis can be found in sheltered, sandy intertidal environments (Demond 1957:296), while Batissa violacea is an occupant of fresh or slightly brackish-water environments (van Bentham Jutting 1953:47, 53). Nerita undata, on the other hand, is most often associated with rocky-shore environments (Morton and Raj n.d.:11; Demond 1957:288), but has also been recorded in association with littorinid snails within the mangrove zone (Demond 1957:288-289). The latter habitat is an unlikely zone of origin in the case of Malaqereqere, given the absence of other mangrove-associated species.

Considering the whole shell assemblage as an aggregate unit, molluscs deriving from the sandy intertidal zone, supplemented by those sourced from the upper-to-mid-intertidal rocky 
shore, contribute the greatest numbers. However, there are variables that may distort this picture. As outlined above in the case of Volivoli II, the lack of fit between Turbo spp. opercula and Turbo spp. shells suggests processing at/near the point of collection. If many of these opercula are associated with reef-flat intertidal Turbo species, then it is likely that other medium-large intertidal reef-flat gastropods will be underrepresented or absent. However, this line of reasoning appears less likely for Malaqereqere than for Volivoli II, as even smaller reef-flat intertidal species are uncommon. In addition, it should be pointed out many of the more common species grouped under 'reef-flat intertidal' in Figure 103 can also be found in the sandy intertidal zone (e.g. Cypraea annulus, C. tigris) or the rocky shore (e.g. Nerita chamaeleon, Nerita albicilla), thus probably overestimating the contribution of the reef-flat intertidal zone at Malaqereqere.

Again following the pattern seen in several of the other Fijian sites, freshwater niches are consistently represented. Comprising 11\% (MNI) of the overall Malaqereqere assemblage, the large bivalve Batissa violacea $(\mathrm{n}=357)$ dominates, supplemented by Melanoides tuberculata $(\mathrm{n}=9)$ and various freshwater neritid taxa (Neritina turrita and Neritodryas cornea). The lack of mangrove-associated taxa once more indicates that freshwater environments are being specifically targeted, rather than being a peripheral zone abutting estuarine areas.

While the Malaqereqere shell sample cannot be broken down into stratigraphic layers to assess change over time, a spit-based comparison sheds some light on temporal patterning. Four taxa were selected for comparison for various reasons. Strombus mutabilis is the most common species associated with the intertidal sandy niche, while Nerita undata can be considered the equivalent species representing the rocky upper-to-mid-intertidal zone. Modiolus philippinarum is not as common as the preceding species, but gives an alternate picture of rocky-shore exploitation when compared with Nerita undata distributions. As discussed above, the case of Turbo spp. opercula is more complicated, with associated species deriving from both the rocky and reef-flat intertidal zones in unknown proportions.

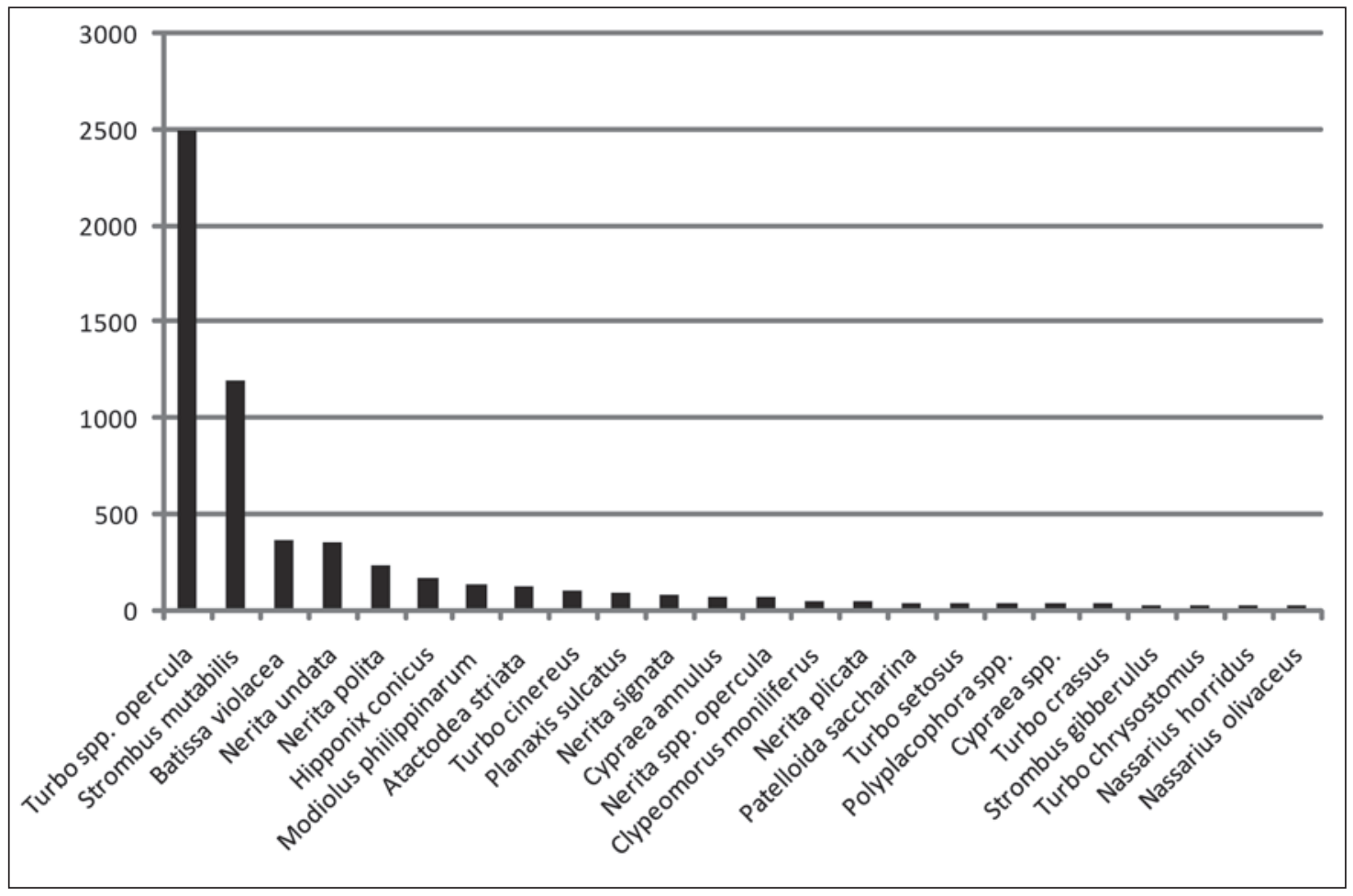

Figure 102. Mollusc species at Malaqereqere represented by 20 or more individuals (MNI). 


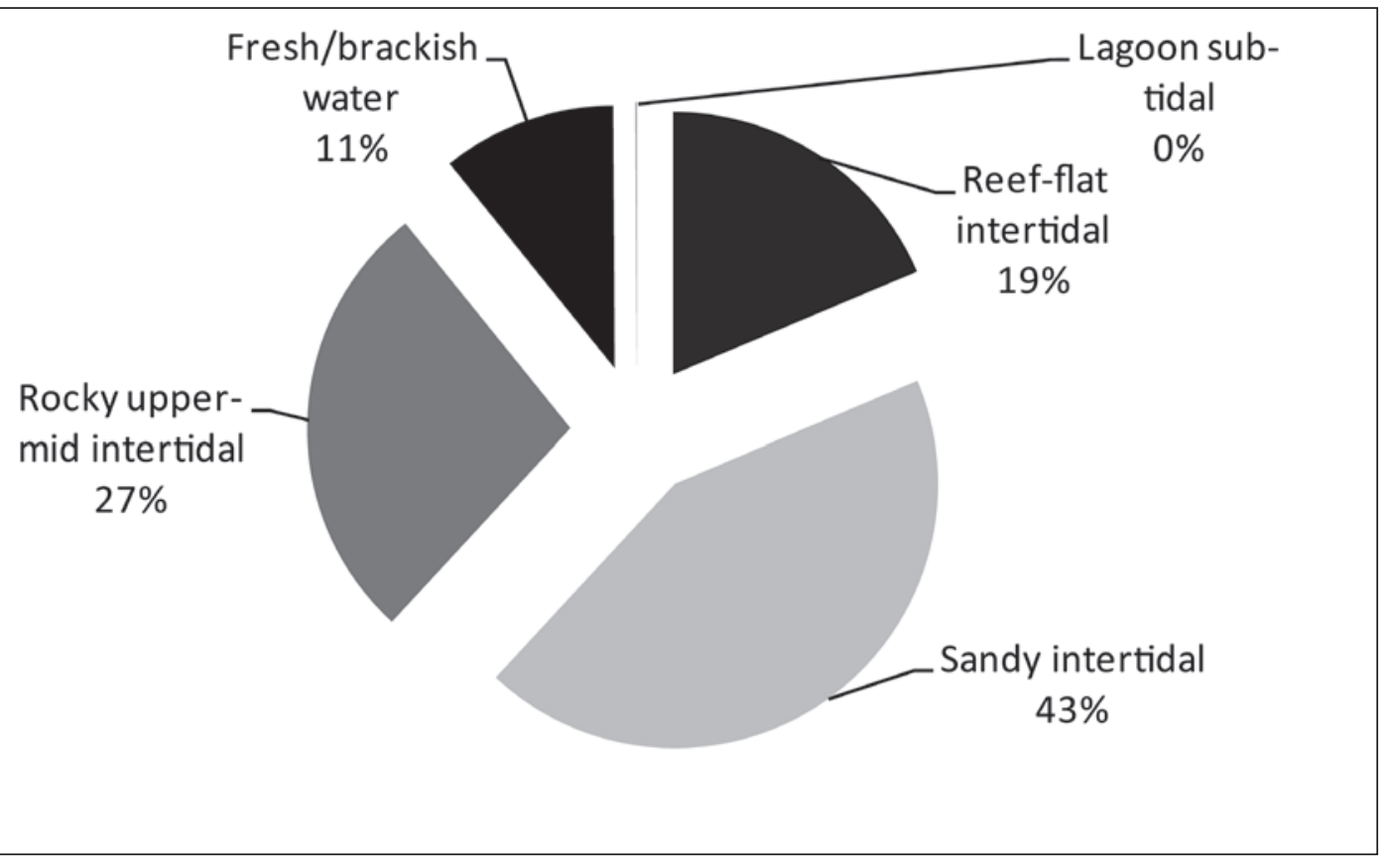

Figure 103. Proportions of different environments represented in the Malaqereqere shell assemblage as calculated through MNI values. Opercula values for Turbo spp. and Nerita spp. have been omitted.

Figure 104 shows the different relative frequencies of the indicator taxa through time at Malaqereqere, while Figure 105 gives absolute frequencies. The Strombus mutabilis values indicate that sandy intertidal environments are locally present and exploited throughout the sequence, and although relative frequencies would suggest this niche was most important mid-sequence, absolute frequencies show this is a feature of sample size. Batissa violacea is also present throughout the sequence, representing the exploitation of freshwater environments. Both relative and absolute frequencies show that this niche received greater focus in the lowest spits of Malaqereqere.

The relationship between Nerita undata and Modiolus philippinarum is intriguing. As mentioned above, Nerita undata is most often associated with rocky-shore environments and a mangrove association is unlikely in the case of Malaqereqere. Modiolus philippinarum is likewise associated with rocky shores, although as pointed out by Gosliner et al. (1996:179), it is sometimes found in association with live coral heads. It is perhaps this more subtle difference in ecology that explains the inverse relationship between the two species shown in both Figures 104 and 105, with Modiolus philippinarum more prevalent towards the bottom of the sequence and Nerita undata only becoming an important contributor in upper levels. However, the rockyshore gastropod Planaxis sulcatus shows spikes in abundance at both the 10-20 cm and 50-60 $\mathrm{cm}$ levels. There are perhaps subtle ecological factors at play with rocky-shore environments in the vicinity of Malaqereqere, but what can certainly be said is that this broad niche was exploited for molluscan resources throughout the sequence.

Finally, while it cannot be determined how far Turbo spp. opercula indicate either rocky intertidal or reef-flat intertidal environments, what can be said is that the upper two spits show the decreasing importance of hard-shore environments in favour of sandy habitats. 


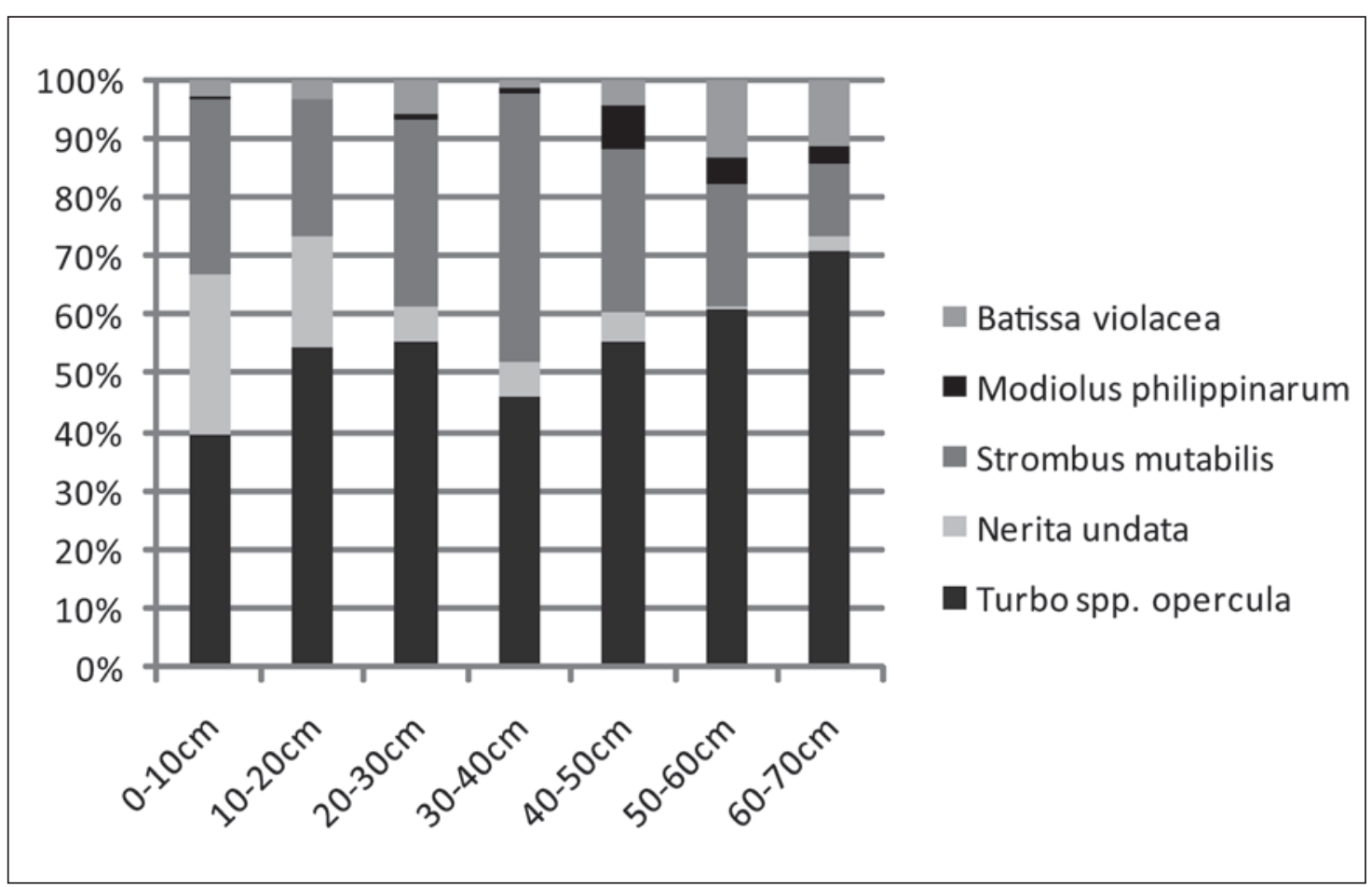

Figure 104. Relative frequencies of major molluscan indicator taxa through time at Malaqereqere shelter - Squares A1 and $\mathrm{A} 2$ combined.

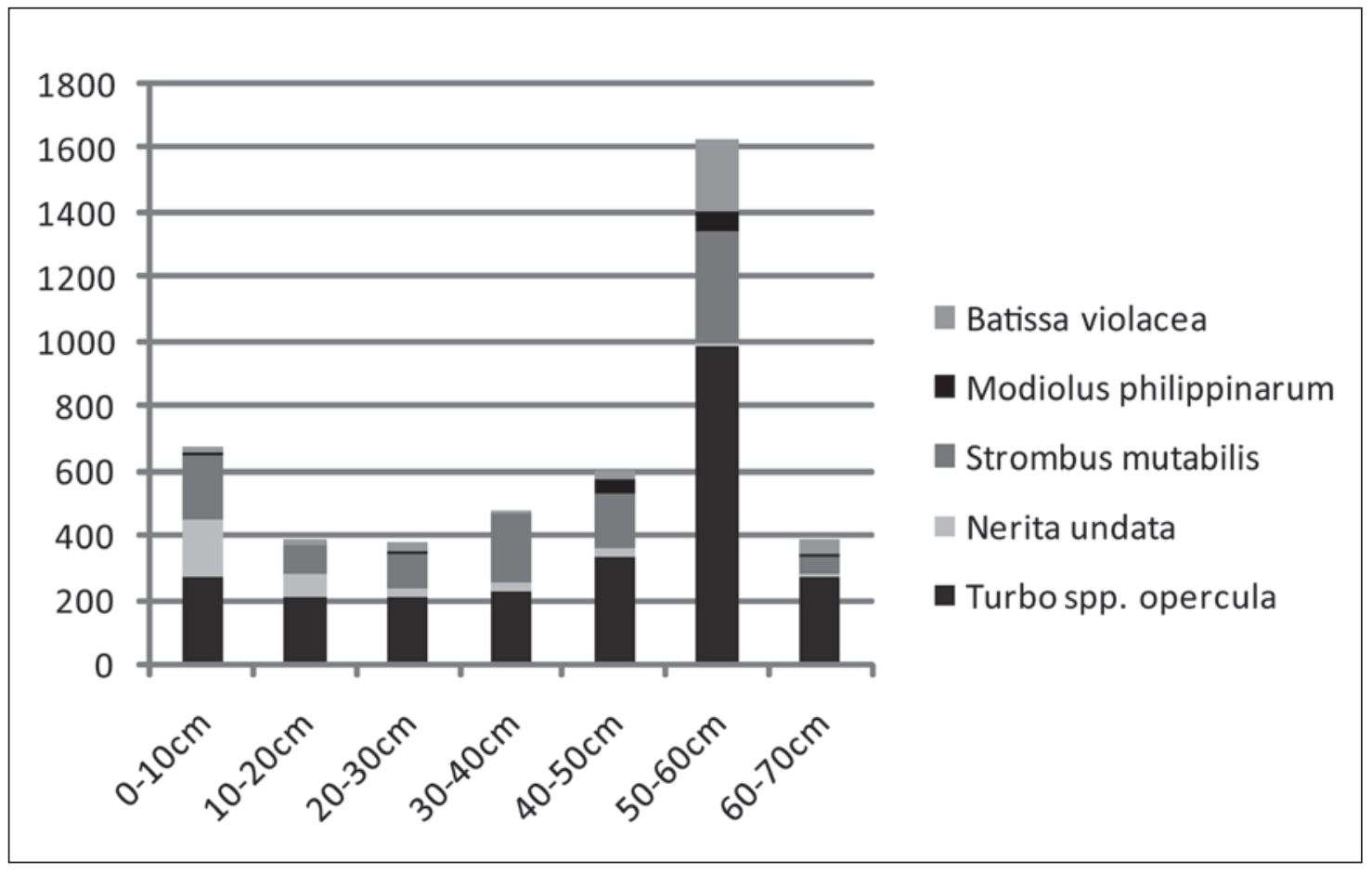

Figure 105. Absolute frequencies of major molluscan indicator taxa through time at Malaqereqere shelter - Squares $\mathrm{A} 1$ and $\mathrm{A} 2$ combined. 


\section{Ugaga}

In total, 121 species of mollusc were identified within the Ugaga sub-sample, which comprised 2061 individuals (MNI). This is a rather high level of diversity when compared with the overall sample size, though it should be noted that the majority of the shell (1320 MNI) comes from four species alone: Nerita polita, Nerita albicilla, Turbo chrysostomus and Turbo cinereus. Figure 106 shows this pattern, along with the totals of other species that contribute 10 or more individuals to the overall sample. In keeping with the ecological proclivities of the four dominant taxa, $75 \%$ of the shell studied from Ugaga derives from the intertidal reef platform, with smaller numbers deriving from upper to mid-intertidal rocks and the sandy intertidal zone (see Figure 107). Eight fragments of Batissa violacea, together with a single Neritina violacea, represent freshwater habitats, which are absent on Ugaga Island, and so must be human introductions. Although there is no apparent use-wear, it is possible that Batissa violacea valves were transported as expedient tools. A single Placostylus sp. shell represents the input of terrestrial habitats, but it is unclear whether Placostylus-bearing habitats were/are present on Ugaga Island.

Before drawing too many conclusions regarding the patterning of molluscan remains at Ugaga, it should be stated that the majority of the shell sample studied does not represent direct human-food refuse. Rather, distinctive patterns of wear around the aperture and body whorl indicate that many univalve shells were used and deposited by terrestrial hermit crabs in the genus Coenobita, and most probably the species Coenobita rugosa. The potential of coenobitid hermit crabs to not only disturb deposits, but to remove midden shell in exchange for worn, hermitted specimens of unknown original provenance, has been theoretically acknowledged in

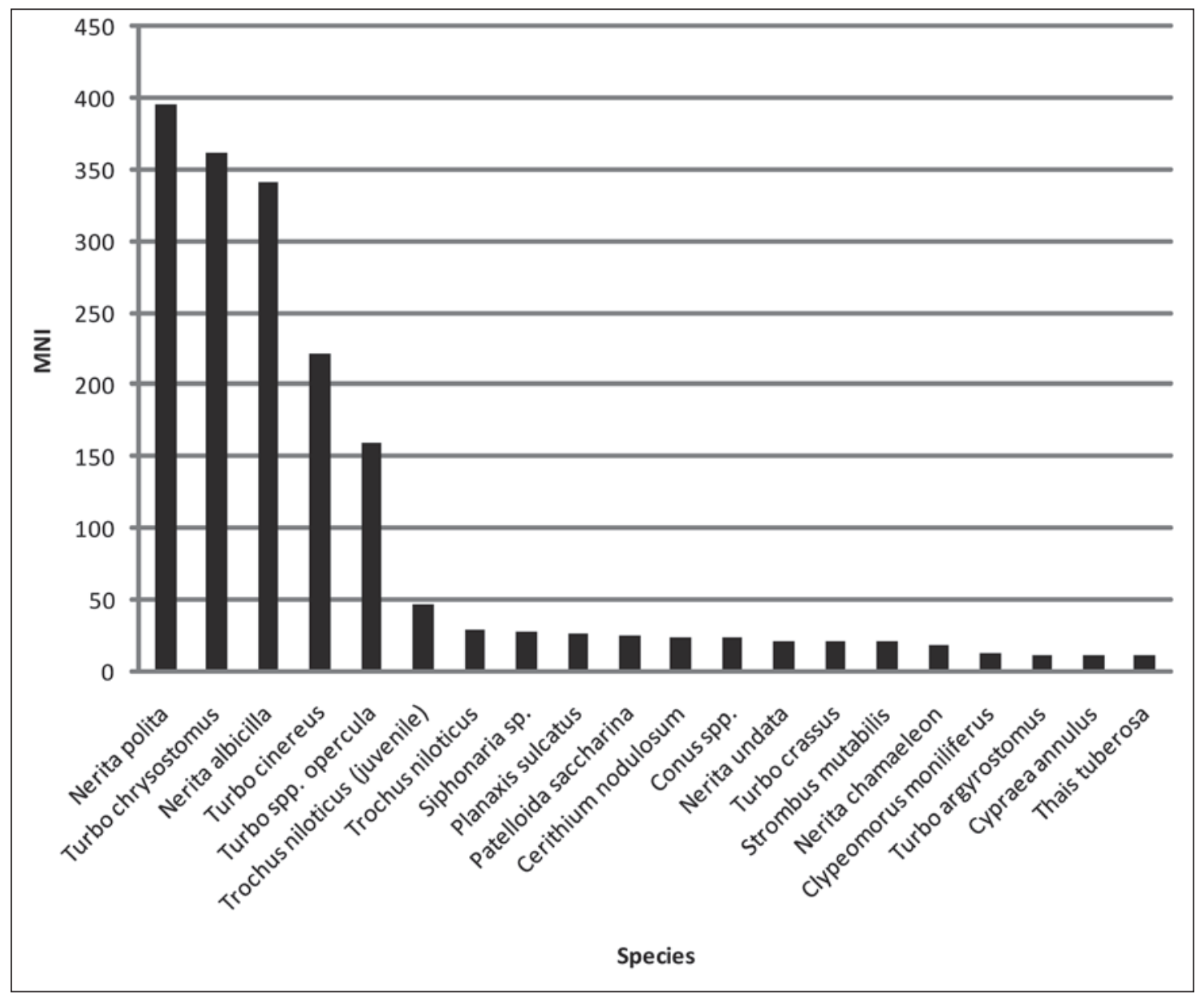

Figure 106. Mollusc species at Ugaga represented by 10 or more individuals (MNI). 
the archaeological literature (Carucci 1992; Reitz and Wing 1999:65-66), and recognised and enfolded into interpretation rarely (but see Walker 1994, 1995 and Scudder and Quitmyer 1998 for palaeontology). Precise ways to recognise shell deposited by terrestrial hermit crabs are outlined in Szabó and Yang (In prep.).

In the case of Ugaga, Figure 108 demonstrates the extent of hermit-crab interference with the archaeological deposits. Such interference goes far beyond the normal bioturbation processes often associated with crabs (e.g. Palmer 1965; Green et al. 1967; Specht 1968, 1985), and has the potential to affect not only the interpretation of human shell-gathering practices, but also a site chronology based on radiocarbon dates obtained on gastropod marine shell. Of the 10 radiocarbon dates on marine shellfish from Ugaga, seven were on the bivalve Tridacna maxima not used by hermit crabs, and two of the univalves (Beta-107953 and ANU-10776) were examined for evidence of aperture damage/modification before sample submission. It should be noted that identification of hermit-crabbed specimens using wear and shell modification indicators was conservative, and actual hermit-crab usage rates are likely to be higher than recorded.

The common Pacific species Coenobita rugosus is the most likely species responsible for shell removal at Ugaga. Depending on the local ecology, different species of Coenobita will favour different shell species. In the case of the ground-dwelling C. rugosus, robust, globose shells with a large interior cavity and circular or D-shaped aperture are preferred (Barnes 1999, 2001), translating to a common preference for species within the Turbinidae and Neritidae (Barnes 1999; see also Kinosita and Akira 1968 and Osorno et al. 1998). Unlike marine hermit crabs (Decapoda: Diogenidae), coenobitid hermit crabs are primarily nocturnal and require freshwater which is held in the shell (Hazlett 1981:4-5; Small and Thacker 1994:171; De Wilde 1973 in Walker 1994; Barnes 1997:138-139), and as such are unlikely to have been the hermit-crab taxa noted during excavation. They have been noted to be strongly attracted to coastal human settlements, which provide a variety of food sources attractive to scavengers as well as dumps of whole shells

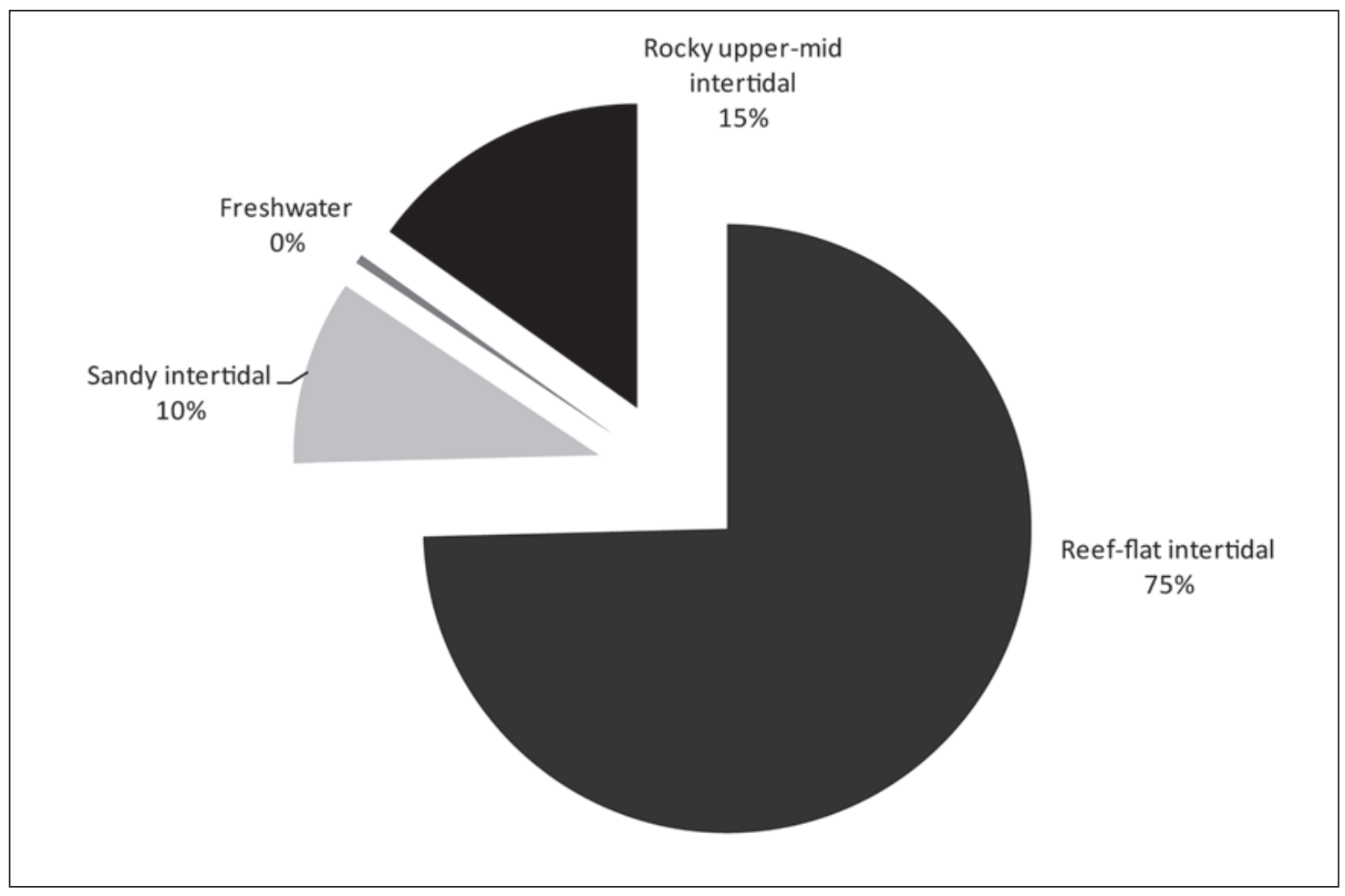

Figure 107. Proportions of different environments represented in the Ugaga shell assemblage as calculated through MNI values. Opercula and shell values for Turbo spp. have been omitted. 


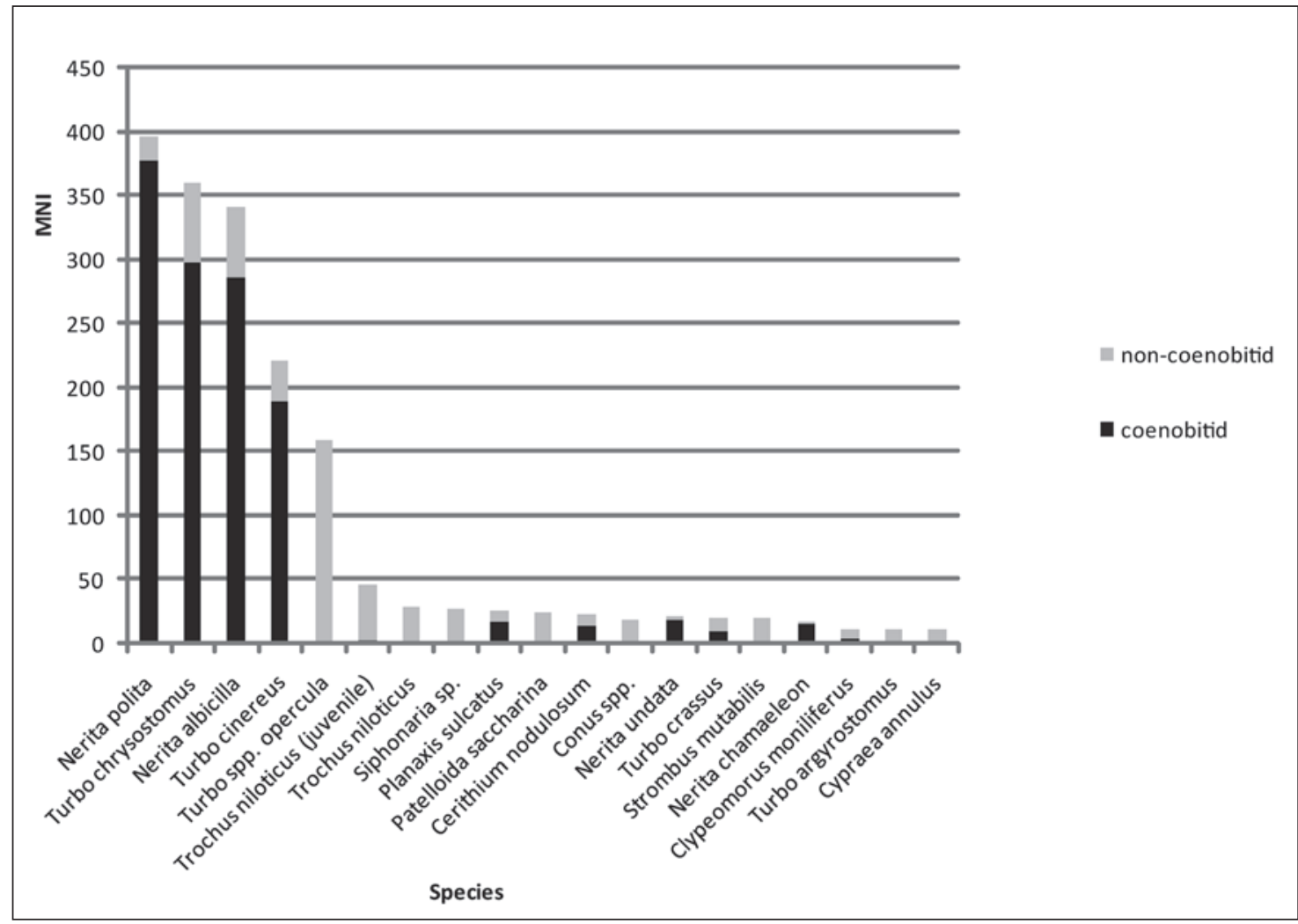

Figure 108. Graph showing the extent of coenobitid hermit-crab shell deposition noted for the major taxa represented at Ugaga.

- a common limiting factor on coenobitid populations in nature (Hazlett 1981:11-13; Barnes 2001). Furthermore, research suggests that $C$. rugosus only approaches shells that have a suitably shaped and sized aperture visible at its eye level (Kinosita and Akira 1968:310, 355). This means that partially buried shells or shells lying with the aperture at a visual angle which precludes size assessment will not be approached, and thus buried or partly buried midden shells are unlikely to be targeted by C. rugosus (see also Hazlett 1981; Barnes 1999).

All of these factors make plain that the shell replacement witnessed for Ugaga is not only a recent activity, but that univalve shell exchange was most likely going on as the midden was being formed.

Few definite conclusions can be drawn about human shell-gathering practices at Ugaga. There is no guarantee that coenobitid crabs deposited shells of the same species they removed. Nevertheless, it has been demonstrated that coenobitids will not cast off a more preferred species of shell for a less preferred one (Thacker 1994; Osorno et al. 1998). Given the preference of C. rugosus for turbinids and neritids, and its dominance within the Ugaga deposits, it can be reasonably safely assumed that these taxa had the highest removal rates. The relatively high incidence of Turbo spp. opercula also attests to the original presence of Turbo spp. within the midden.

\section{Qaranioso II}

The small shell sample from Qaranioso II contains a total of 111 individuals (MNI) spread across 23 different species. Soft-shore bivalves are strongly dominant, with Gafrarium tumidum, Anadara antiquata and Atactodea striata all well represented, supplemented by Codakia tigerina, Tellina palatum and Fragum unedo (see Figure 109). Occasional specimens derive from reefplatform intertidal or rocky-shore environments, but soft-shore species account for $89 \%$ of the total shell sample (see Figure 110). 
The majority of shell was associated with Layers 1 and 2, with only two fragments (Tellina palatum and Gafrarium tumidum) being found in Layer 3. There is little apparent difference in molluscan concentrations or representation between Layers 1 and 2.

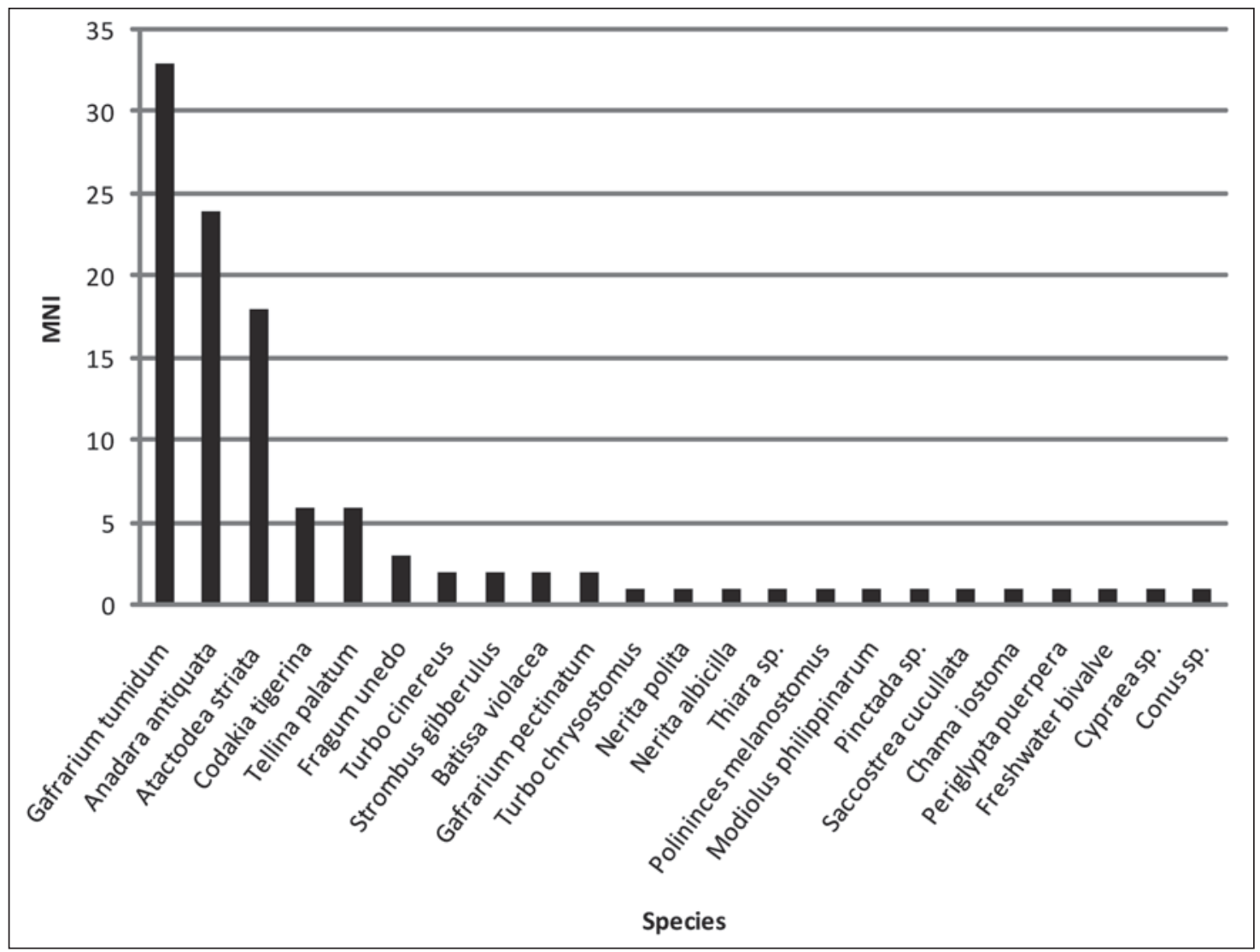

Figure 109. Abundances of all molluscan remains recovered from the Qaranioso II (MNI).

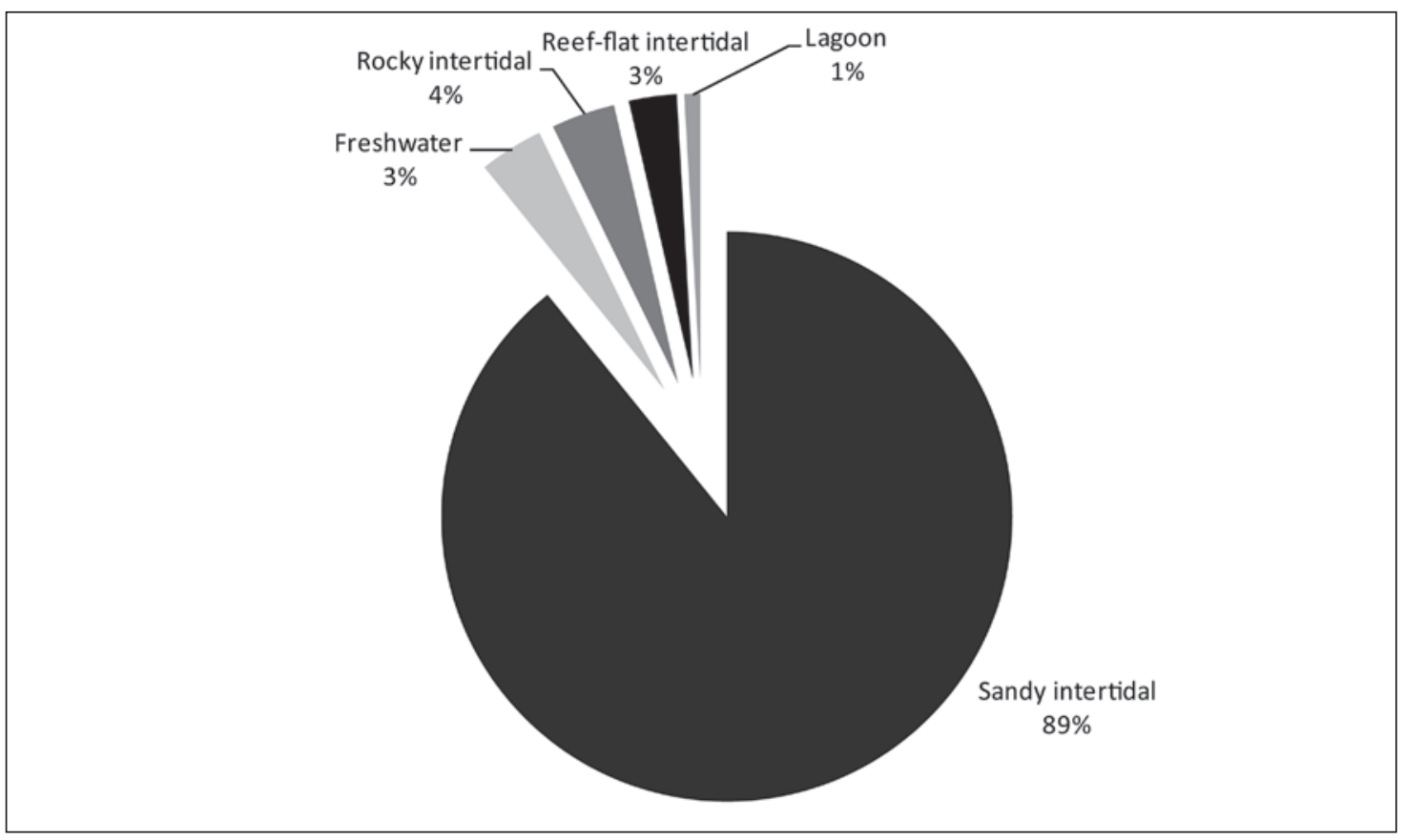

Figure 110. Proportions of different environments represented in the Qaranioso II shell assemblage as calculated through MNI values. Opercula values for Turbo spp. have been omitted. 


\section{Discussion}

When all the samples discussed above are considered as a whole, the most notable feature is the sheer diversity of species represented. Figure 111 shows the relationship between sample size and species diversity for all samples bar Tuvu and Qaranioso I. Given that species richness is closely correlated with sample size, it is unsurprising that some of the most diverse samples are the larger ones: Ugaga, Votua and Natunuku. However, Figure 111 also shows that some of the smaller samples are more diverse than their larger counterparts.

Although the Votua Lapita sample was the largest analysed, it falls behind Ugaga and Natunuku in terms of species diversity, but also behind the much smaller assemblages from Malaqereqere and Volivoli II. This would appear to be at least partially attributable to the spread of mollusc-bearing niches used by ancient shell-gatherers. Nearly $75 \%$ of the Votua assemblage derives from the sandy intertidal zone, with a strong focus on the collection of the muddysand bivalve Anadara antiquata. The only other assemblages that show such a strong collecting focus on a single littoral niche are Qaranioso II, with $89 \%$ of specimens derived from the sandy intertidal, and Ugaga, where $75 \%$ of individuals are drawn from the reef-flat intertidal zone. At Ugaga, the reef-flat niche is represented by a variety of species, with the representation being skewed to an unknown degree by hermit-crab shell deposition.

At Qaranioso II, three species (Gafrarium tumidum, Anadara antiquata and Atactodea striata) combine to elevate the soft shore to a position of prominence within the overall collecting structure. Thus, Votua is unique among the assemblages studied in having such a concerted focus on a single species, and it is the only site for which a premeditated, focused collecting strategy can be argued. It is also the only single-phase Lapita site excavated, and other EPF sites with Lapita age materials, such as Natunuku, Kulu Bay and Ugaga, contain evidence of disturbance that might have obscured the pattern of shellfish gathering during the colonisation phase.

All other sites show a collecting pattern that is considerably more fine-grained. Species are taken from the environment in the relative proportions in which they naturally occur. This appears to be as true of species representation as it is of size classes within a population. This approach to mollusc collection diverges not only from the focused approach seen at Votua, but also from other recorded patterns, where large individuals are taken regardless of species (e.g. Anderson 1981). Indeed, the strategy manifest for the bulk of the Fijian shell-midden samples can be fairly categorised as 'reef-sweeping'.

This observation has important implications for the discussion of potential human impact on mollusc populations, and for statements that link a decrease in average size over time with predation pressure (e.g. Bedford 2007:189 for Lapita, contrasted with Allen 2000:149 and references therein for Pleistocene Near Oceania). Certainly, a gathering strategy that focuses on the removal of only the largest (and most fecund) individuals of a population will display a different final structure from a strategy in which large and small, mature and immature specimens have been harvested more or less equally. Exactly what such strategies may produce in terms of a final demographic structure will depend not only on the particular behaviours and population dynamics of the species under discussion, but also the local environmental variables.

There seems to be no major temporal trend apparent in the data, nor particular differences between open and shelter sites. Rather, notable tendencies such as high species diversity and multiple coastal niche exploitation seem to be reflected across all samples to a greater or lesser degree. Occasional specimens indicate that molluscan-bearing freshwater environments were generally accessible, but barring the regular occurrence of the bivalve Batissa violacea, were not exploited to any great degree. The same can be said of exploitation of terrestrial molluscs, with the possible exception of Volivoli II. 


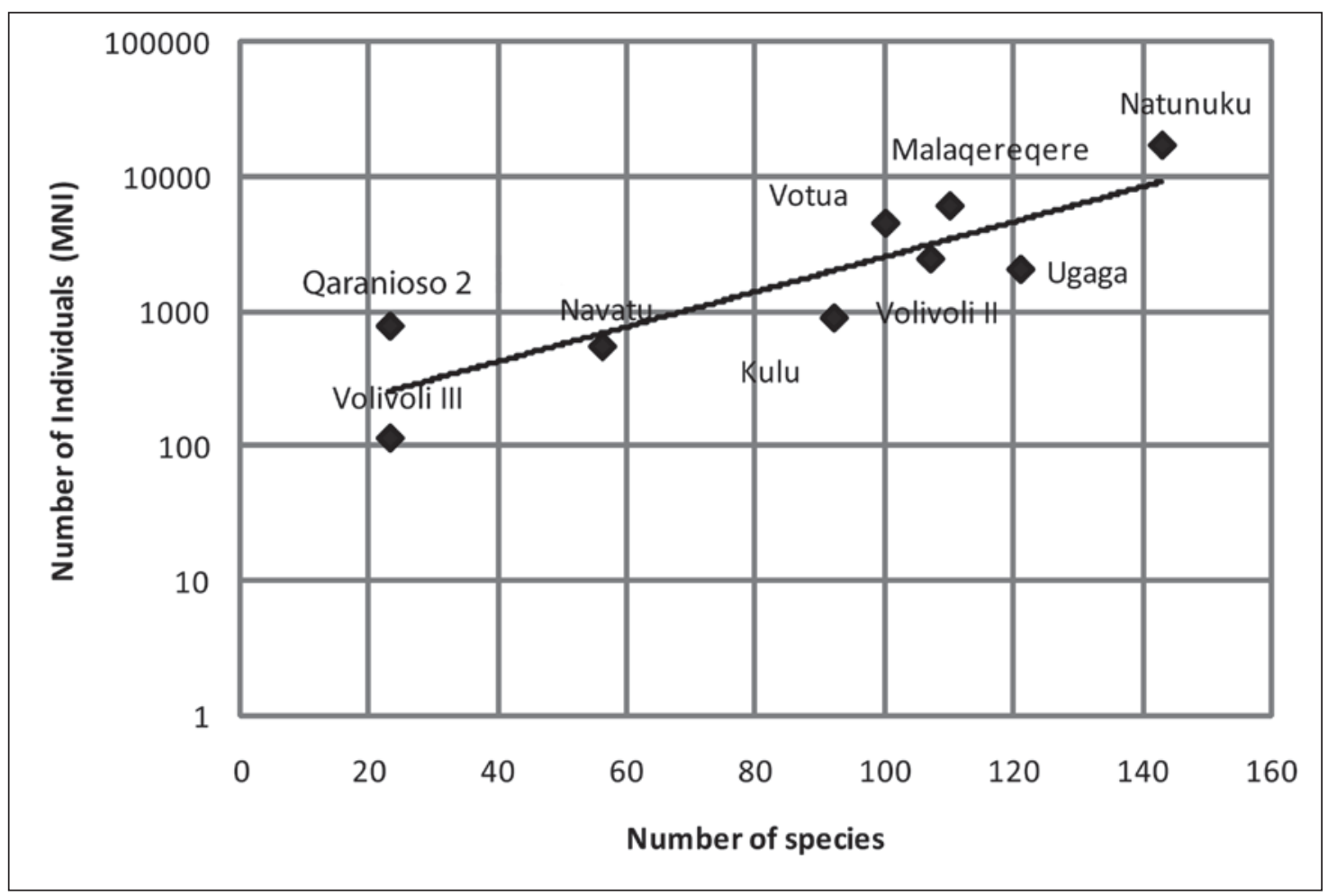

Figure 111. Graph to show the relationship between sample size (total MNI) and species diversity for all samples except Tuvu and Qaranioso I. Note that the Y-axis is a $\log$ scale.

\section{Conclusion}

The broad picture presented by the results of analysis of the molluscan remains from the EPF sites is a consistent one. A general low level of selectivity for particular species or size classes, combined with exploitation of a range of littoral habitats, has resulted in very diverse samples. Interestingly, diversity is the key point stressed by Burrows (1940:12) regarding molluscgathering strategies in Fiji in the ethnographic present: '. . . it would be wrong to say that any [molluscs] are exempt from finding their way into the cooking pot.' Burrows (1940:12) goes on to state that various species are particularly prized, but close reading indicates that these are species (e.g. Anadara antiquata, Batissa violacea and Gafrarium tumidum) gathered for sale at the markets, rather than for family consumption.

Perhaps it is the common assumption that molluscs represent a labour-intensive and poor source of food that leads to the presupposition of a high level of selectiveness (see Erlandson (2001) for a review of the status of molluscs in archaeological subsistence arguments). What the Fijian assemblages clearly demonstrate is that all molluscs, large and small, were collected, and that selectivity cannot be assumed at the outset. This conclusion indicates that analysts of archaeological shell must completely identify their samples, and that field archaeologists should sample shell midden to a sufficient degree and not discard shell in the field. 


\section{References}

Abbot, R.T. and Dance, S.P. 1982. Compendium of seashells. E.P. Dutton, New York.

Allen, J. 2000. From beach to beach: The development of maritime economies in prehistoric Melanesia. In: O'Connor, S. and Veth, P. (eds), East of Wallace's Line: Studies of past and present maritime cultures of the Indo-Pacific region, pp. 139-176. A.A. Balkema, Rotterdam and Brookfield.

Allen, M.S. 2003. Human impact on Pacific nearshore marine ecosystems. In: Sand, C. (ed), Pacific archaeology: Assessments and prospects, pp. 317-325. Service des Musées et du Patrimoine, Nouméa.

Anderson, A. 1981. A model of prehistoric collecting on the rocky shore. Journal of Archaeological Science 8: 109-120.

Anderson, A., Clark, G. and Worthy, T. 2000. An inland Lapita site in Fiji. Journal of the Polynesian Society 109: 311-316.

Barnes, D.K.A. 1997. Ecology of tropical hermit crabs at Quirimba Island, Mozambique: Distribution, abundance and activity. Marine Ecology Progress Series 154: 133-142.

Barnes, D.K.A. 1999. Ecology of tropical hermit crabs at Quirimba Island, Mozambique: Shell characteristics and utilisation. Marine Ecology Progress Series 183: 241-251.

Barnes, D.K.A. 2001. Hermit crabs, humans and Mozambique mangroves. African Journal of Ecology 39: 241-248.

Bedford, S. 2007. Crucial first steps into Remote Oceania. In: Chiu, S. and Sand, C. (eds), From Southeast Asia to the Pacific: Archaeological perspectives on the Austronesian expansion and the Lapita Cultural Complex, pp. 185-213. Center for Archaeological Studies, Academia Sinica, Taipei.

Broughton, J.M. 1999. Resource depression and intensification during the Late Holocene, San Francisco Bay: Evidence from the Emeryville shellmound vertebrate fauna. University of California Publications, Anthropological Records No. 32. University of California, Berkeley.

Burrows, Commander W. 1940. Notes on molluscs used as food by the Fijians. Transactions and Proceedings of the Fiji Society 2(1): 12-14.

Carucci, J. 1992. Cultural and natural patterning in prehistoric marine foodshell from Palau, Micronesia. Unpublished PhD thesis, Southern Illinois University at Carbondale.

Cernohorsky, W.O. 1972. Marine shells of the Pacific, Volume II. Pacific Publications, Sydney.

Cernohorsky, W.O. 1978. Tropical Pacific marine shells. Pacific Publications, Sydney and New York.

Claassen, C. 2000. Quantifying shell: Comments on Mason, Peterson and Tiffany. American Antiquity 65(2): 415-418.

Clark, G., Anderson, A. and Matararaba, S. 2001. The Lapita site at Votua, northern Lau Islands, Fiji. Archaeology in Oceania 36: 134-145.

Dance, S.P. 1977. The encyclopedia of shells. Australia and New Zealand Book Company, Sydney.

Demond, J. 1957. Micronesian reef-associated gastropods. Pacific Science XI(3): 275-341.

Erlandson, J. 2001. The archaeology of aquatic adaptations: Paradigms for a new millennium. Journal of Archaeological Science 9(4): 287-350.

Glassow, M.A. 2000. Weighing vs. counting shellfish remains: A comment on Mason, Peterson and Tiffany. American Antiquity 65(2): 407-414.

Gosliner, T.M., Behrens, D.W. and Williams, G.C. 1996. Coral reef animals of the Indo-Pacific. Sea Challengers, Monterey CA.

Grayson, D.K. 1984. Quantitative zooarchaeology: Topics in the analysis of archaeological faunas. Academic Press, Orlando FL and London.

Green, R.C., Green, K., Rappaport, R.A., Rappaport, A. and Davidson, J. 1967. Archaeology on the island of Mo'orea, French Polynesia. Anthropological Papers of the American Museum of Natural History 51(2).

Habe, T. 1964. Shells of the Western Pacific in color, Volume 2. Hoikusha Publishing Company, Osaka. Hazlett, B.A. 1981. The behavioural ecology of hermit crabs. Annual Review of Ecology and Systematics 12: $1-22$. 
Hinton, A. 1972. Shells of New Guinea and the Central Pacific Indo-Pacific. Robert Brown and Associates and Jacaranda Press, Port Moresby and Milton QLD.

Kinosita, H. and Akira O. 1968. Analysis of shell-searching behaviour of the land hermit-crab, Coenobita rugosus $\mathrm{H}$. Milne Edwards. Journal of the Faculty of Science, University of Tokyo: Section IV Zoology 11(3): 293-358.

Kira, T. 1965. Shells of the Western Pacific in color, Volume 1. Revised edition. Hoikusha Publishing Company, Osaka.

Kress, J.H. 2000. The malacoarchaeology of Palawan Island. Journal of East Asian Archaeology 2(1): 285-328.

Mason, R.D., Peterson, M.L. and Tiffany, J.A. 1998. Weighing vs. counting: Measurement reliability and the California school of midden analysis. American Antiquity 63(2): 303-324.

Mason, R.D., Peterson, M.L. and Tiffany, J.A. 2000. Weighing and counting shell: A response to Glassow and Claassen. American Antiquity 65(4): 757-761.

Morton, J. and Raj, U. n.d. The shore ecology of Suva and South Viti Levu. University of the South Pacific. Introduction to Zoning and Reef Structures - Soft Shores, Book One. Suva, Fiji.

Osorno, J-L., Fernández-Casillas, L. and Rodríguez-Juárez, C. 1998. Are hermit crabs looking for light and large shells?: Evidence from natural and field-induced shell exchanges. Journal of Experimental Marine Biology and Ecology 222(1998): 163-173.

Palmer, B. 1965. Excavations at Karobo, Viti Levu. New Zealand Archaeological Association Newsletter 8: 26-33.

Palmer, J.B. 1968. Excavations at Karobo, Viti Levu. New Zealand Archaeological Association Newsletter 8(2): $26-34$.

Reitz, E.J. and Wing, E.S. 1999. Zooarchaeology. Cambridge University Press, Cambridge, New York and Melbourne.

Scudder, S.J. and Quitmyer, I.R. 1998. Evaluation of evidence for pre-Columbian occupation at Great Cave, Cayman Brac, Cayman Islands. Caribbean Journal of Science 34(1-2): 41-9.

Small, M.P. and Thacker, W.T. 1994. Land hermit crabs use odors of dead conspecifics to locate shells. Journal of Experimental Marine Biology and Ecology 182(1994): 169-182.

Specht, J. 1968. Preliminary report of excavations on Watom Island. Journal of the Polynesian Society 77(2): 117-134.

Specht, J. 1985. Crabs as disturbance factors in tropical archaeological sites. Australian Archaeologist 21: $11-18$.

Szabó, K. 1999. Shellfish gathering and foraging behaviour: An investigation into optimality and mollusc remains from prehistoric Motutapu Island. Unpublished BA(hons) thesis, Department of Anthropology, University of Auckland.

Szabó, K. 2001. The reef, the beach and the rocks: An environmental analysis of mollusc remains from Natunuku, Viti Levu, Fiji. In: Clark, G.R., Anderson, A.J. and Vunidilo, T. (eds), The Archaeology of Lapita Dispersal in Oceania, pp. 159-166. Pandanus Books, Canberra.

Szabó, K. and Yang, H-Y. S. In prep. Terrestrial hermit crab interference in archaeological shell deposits.

Thacker, R.W. 1994. Volatile shell-investigation cues of land hermit crabs: Effect of shell fit, detection of cues from other hermit crab species, and cue isolation. Journal of Chemical Ecology 20(7): $1457-1482$.

Van Benthem Jutting, W.S.S. 1953. Systematic studies on the non-marine mollusca of the IndoAustralian Archipelago; part IV: Critical revision of the freshwater bivalves of Java. Treubia 21(1): $19-73$.

Walker, S.E. 1994. Biological remanie: Gastropod fossils used by the living terrestrial hermit crab, Coenobita clypeatus, on Bermuda. Palaios 9: 403-412.

Walker, S.E. 1995. Taphonomy of modern and fossil intertidal gastropod associations from Isla Santa Cruz and Isla Santa Fe, Galápagos Islands. Lethaia 28: 371-382. 
terra australis 31 